\title{
EARLY CHILDHOOD EDUCATORS' PERCEPTIONS OF THEIR ROLES AND RESPONSIBILITIES IN ONTARIO'S FULL DAY KINDERGARTEN PROGRAM
}

by

\author{
Rabeya Hossain
}

Master of Science in Early Childhood Development, BRAC University, Bangladesh, 2011

\author{
A Major Research Paper \\ Presented to Ryerson University \\ In partial fulfillment of the requirements for the degree of \\ Master of Arts \\ In the Program of \\ Early Childhood Studies
}

Toronto, Ontario, Canada, 2014

CRabeya Hossain 2014 


\section{Author's Declaration}

I hereby declare that I am the sole author of this MRP. This is a true copy of the MRP, including any required final revisions.

I authorize Ryerson University to lend this MRP to other institutions or individuals for the purpose of scholarly research.

I further authorize Ryerson University to reproduce this MRP by photocopying or by other

means, in total or in part, at the request of other institutions or individuals for the purpose of scholarly research.

I understand that my MRP may be made electronically available to the public. 


\title{
EARLY CHILDHOOD EDUCATORS’ PERCEPTIONS OF THEIR ROLES AND RESPONSIBILITIES IN ONTARIO’S FULL DAY KINDERGARTEN PROGRAM
}

CRabeya Hossain 2014

Masters of Arts

Early Childhood Studies

Ryerson University

\begin{abstract}
The purpose of this qualitative study was to understand early childhood educators' perceptions of their roles and responsibilities based on their lived experiences in Ontario’s full day kindergarten (FDK) program. The theoretical framework that underpinned my study is post-colonial theory and Foucault’s post-structural concept of “power/knowledge” which offered different perspectives to understand how ECEs' shaped their perceptions. Key messages from the findings suggest despite challenges within the FDK program, ECEs recognized and acknowledged their complementary roles within the teaching team, and identified the need for professional recognition of their work. The key messages further suggested that principals as the leaders of the school need to have a greater understanding about ECEs' roles, and the relationship between the educators. The recognition of the role and knowledge that ECEs contribute to FDK programs is crucial in order to facilitate collaboration between the educators within the teaching team.
\end{abstract}




\section{Acknowledgements}

My family- Thank you for your love, support, understanding and patience. Without your support I would not be able to write this paper.

Zeenat- Thank you for supporting me to make my dream come true. Thank you for enabling me to work in the Schools at the Centre project. Thank you for guiding me to become an independent learner and explore my potentialities.

Mehru- Thank you for sharing your knowledge and passion in research. You encouraged me to undertake this project and I thank you for that.

The participants- Thank you for your consent to participate in this study and sharing your experiences.

Natasha- Thank you for sharing all those strategies that helped me to write this paper.

Shelly- I thank you for your continuous support and encouragement.

My peers- Thank you so much for believing in me. Often, I felt this project was too challenging for me, and you always encouraged and supported me to keep going until the very end. 


\section{Table of Contents}

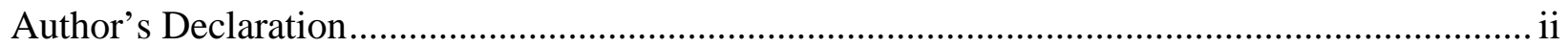

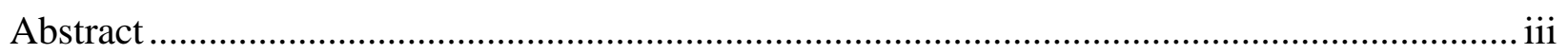

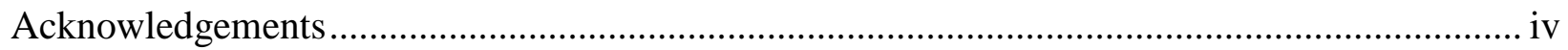

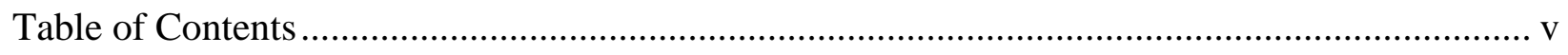

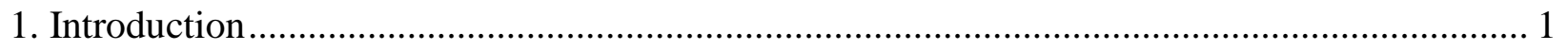

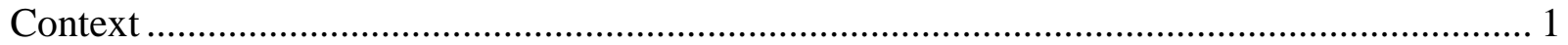

My interest in the Full Day Kindergarten program ......................................................... 5

Statement of Problem ................................................................................................. 7

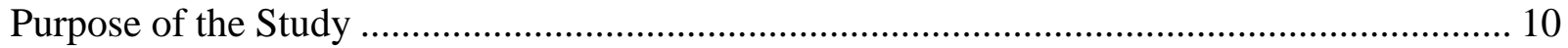

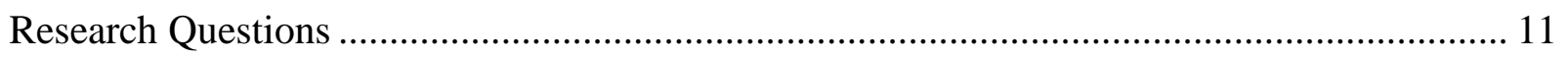

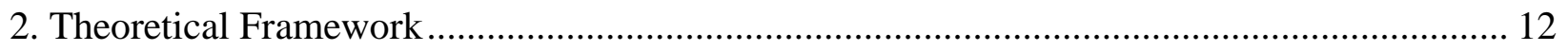

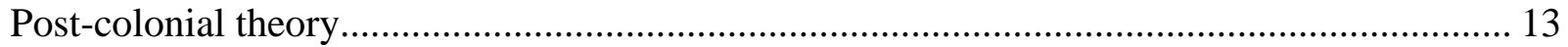

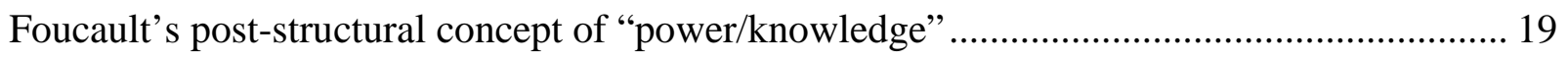

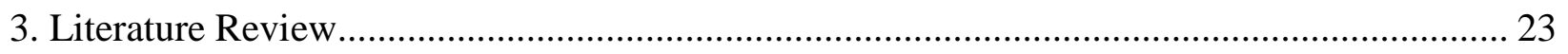

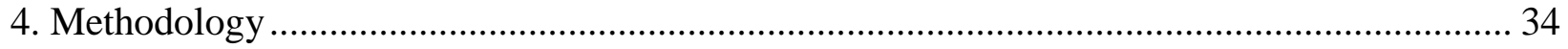

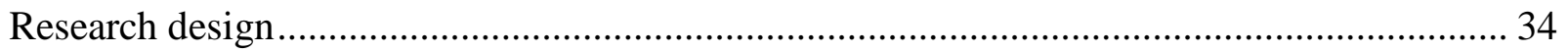

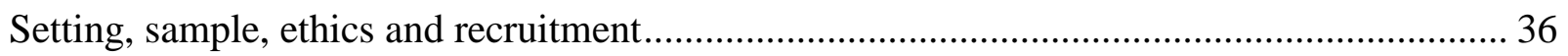

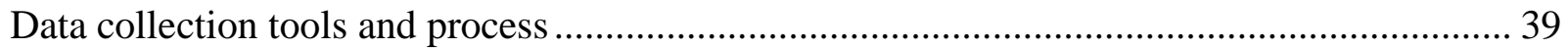

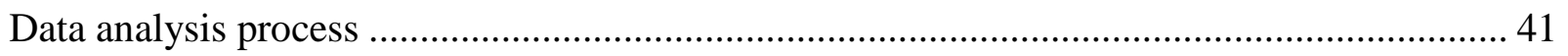

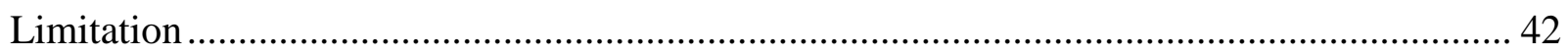

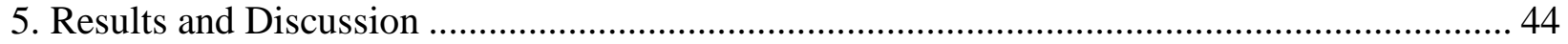

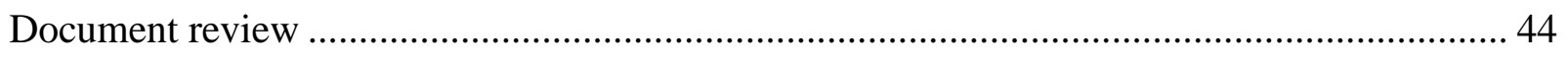

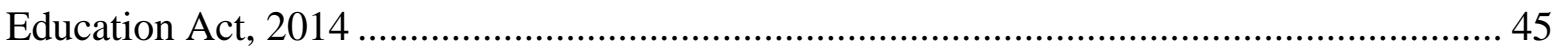

Supporting the Ontario leadership strategy: Principals wants to know: Supporting educator

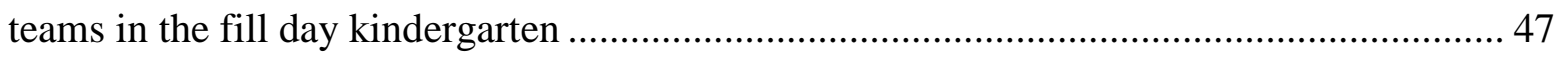


Code of Ethics and Standards of Practice of Early Childhood Educators in Ontario and the Ethical Standards for Teaching Profession and Standard of Practice for Teaching Profession

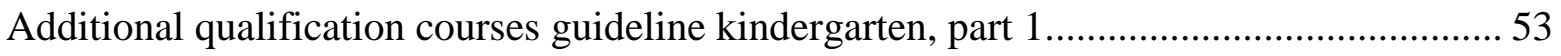

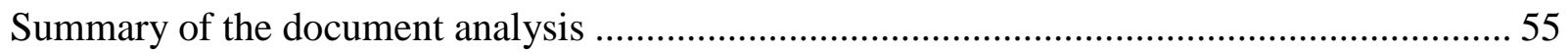

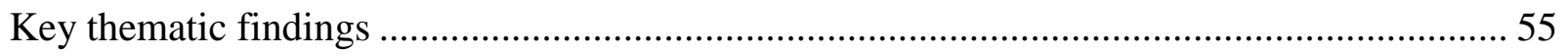

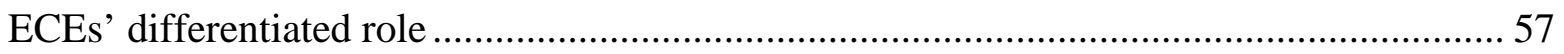

Analysis of theme with theory, literature and document review .................................. 64

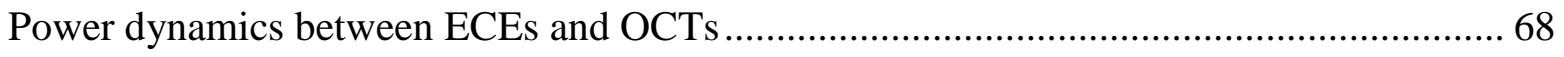

Analysis of theme with theory, literature and document review ................................. 70

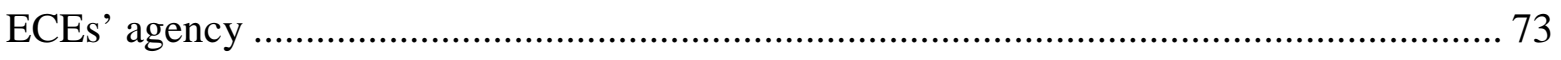

Analysis of theme with theory, literature and document review ................................. 78

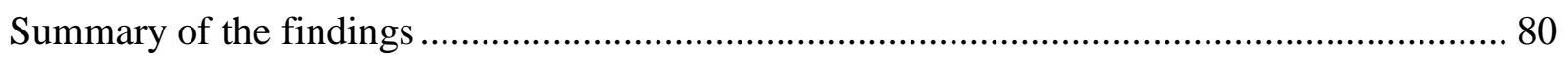

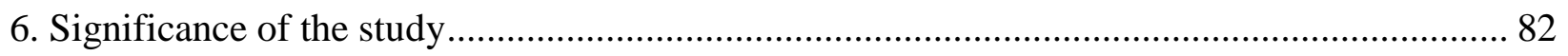

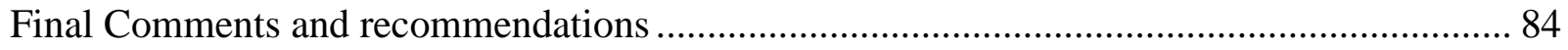

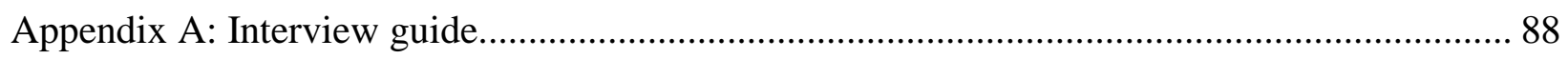

Appendix B: Focus Group Discussion Question guide ..................................................... 89

Appendix C: Recruitment email for potential participants for phone interview ....................... 90

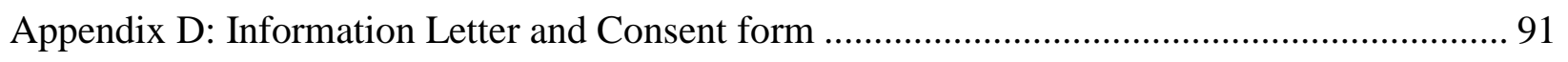

Appendix E: Notice for recruitment of participant for phone interview .................................. 95

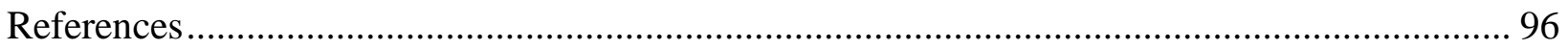




\section{Introduction}

\section{Context}

September 2010 was a significant milestone in the history of education in Canada as the implementation of full day kindergarten (FDK) program moves early childhood education into the realm of education (Cantalini-Willams \& Telfer, 2010). The Government of Ontario launched the program in elementary schools in 2010 with an expectation of full implementation by fall 2014 (Pelletier, 2013). The aim of FDK is to deliver a comprehensive educational program for young children in Ontario under the Ministry of Education to ensure universal access and public accountability (Gananathan, 2011). The implementation of full day kindergarten introduced an important change in the history of education and care in Canada, bringing together the shared responsibility of teacher and early childhood educator to plan and deliver the full day program.

Such a bold change affecting young children and early childhood professionals across the province has not been introduced since the initial implementation of the junior kindergarten in the middle of the twentieth century (Cantalini-Williams \&Telfer, 2010). In 2009, Dr. Charles Pascal, the Premier's special advisor on early learning, outlined a comprehensive plan of action regarding the implementation of provincial government's early learning vision in his report entitled With Our Best Future in Mind, Implementing Early Learning in Ontario (2009).He proposed a full-day learning for 4- and 5- year- olds through a seamless and integrated system that also includes proposals to support preschool aged children and their families. The report presented “compelling research” (Cantalini-Williams \&Telfer, 2010, p. 4) with evidence on the benefits of early intervention for young children, and recommended an integrated early years system in Ontario through amalgamation of education and childcare. As a result, the Full-Day 
Early Learning Statute Law Amendment Act, 2010was introduced and authorized school boards with the responsibility to implement full-day learning including the availability of before and after school extended day program for 4- and 5- year- olds through an teaching team of Early Childhood Educator(ECE) and Ontario Certified Teacher (OCT) (Cantalini-Williams \&Telfer,2010; Pascal, 2009).

The teaching team comprised of ECE and OCT recognized as "essential in providing an optimal FDK learning environment” (Ministry of Education, 2013, p. 13) is a unique feature of FDK combining the expertise of ECE and OCT. The technical team was expected to deliver the FDK program (Ministry of Education, 2013). Pascal's (2009) recommendation for the implementation of FDK places two educators, with distinct differences in their training and experiences, into a collaborative structure (Callaghan, 2012) of educator team. Based on Pascal's (2009) recommendations, Bill 242 (Ministry of Education, 2010)outlined the roles and responsibilities of the educator team to "coordinate" and "cooperate” (Ministry of Education, 2010,p. 4) in planning and implementing daily activities, organizing the learning environment, communicating families, and observing, monitoring and assessing the development of children in the FDK classroom. In addition, OCTs' lead role in preparing report card, instruction, training and assessment of the students, and ECEs' lead responsibilities in delivering the extended day program were also mentioned in the Bill 242 (Ministry of Education, 2010). The purpose of introducing the teaching team was to bring each educator's unique strengths and professional training in a "collaborative and complementary” (Ontario Ministry of Education, 2010, p. 10) partnership to contribute to support children's learning in the FDK classroom. The FDK program aimed to establish a learning environment for the 4- and 5-year-olds that encourage their curiosity through play-based approach and scaffolding by the educator team in order to build a 
solid foundation for future learning. Based on professional training and experiences, specific roles were assigned to each member of the teaching team.

According to Early Childhood Educators Act (2007), ECEs must be registered members of the College of Early Childhood Educators (CECE) to use the professional title of Early Childhood Educators. In addition, ECEs working in FDK must be regulated under the Early Childhood Educators Act (Government of Ontario, 2007). To register with the college, ECEs need a minimum of two years post secondary diploma in early childhood education or equivalent (Gananathan, 2011). The Early Childhood Education program prepares ECEs to work with infants, toddlers, pre-school and school age children and their families in a variety of settings (Ontario Ministry of Training, colleges and Universities, 2012). According to Government of Ontario (2007), the roles and responsibilities of the ECE outlined in the act include planning and delivering comprehensive play-based learning and care program for children to promote their holistic development, assessment of the program and progress of the children, and communicating with the parents.

On the other hand, the OCTs working in the FDK must be registered with the Ontario College of Teachers and governed under the Education Act (Government of Ontario, 2014). They must have a teaching certificate obtained from completing at least one year of study in a faculty of education in addition to a minimum of a 3-year post-secondary degree (Ontario College of Teachers, 2014). The completion of Primary/junior certification enables teachers to teach grades from Junior Kindergarten to Grade 6.According to the Education Act, "the duties of the OCTs incorporate teaching classes/subjects assigned by the principals, encouraging students towards their learning, conducting classes following the timetable, maintaining discipline during and outside the teaching time in school and attending professional development activities 
arranged by the board” (Government of Ontario, 2014, 264.1). As mentioned before, delivering curriculum through the teaching team was one of the key aspects of the FDK program to move away from teacher-centered route learning to play-based active leaning environment through “expert scaffolding by the educators’ team” (Pelletier, 2013, p.2).

The purpose of both CECE and Ontario College of Teachers (OCT)is to regulate the practice of and govern its members, provides opportunity for ongoing education, establish and implement professional and ethical standards, receive and investigate complaints, encourage high standards and quality assurance in relation to the ECEs, and speak to the public on behalf of them. In addition, the Ontario College of Teachers aims to “develop, provide, and accredit educational programs leading to certificates of qualification additional to the certificate required to the membership” (Government of Ontario, 2009, section 3.1). As the proposed study uses a post-colonial and post-structural lens (Bhabha, 1994; Foucault, 1980; Said,1979) understanding the professional training, educational qualifications and regulatory bodies of ECE and OCT was instrumental for gaining a deeper understanding of how ECEs interpret their new roles and responsibilities in the context of FDK program. A post-colonial perspective supports an understanding of how often Educators' cultural and historical background intrude as they shape their new identities within the FDK program.

Combining the expertise of OCT and ECE through a teaching team "in a legislated duty to cooperate” (Pelletier, 2013, p.2) made Ontario’s FDK program different from many other FDK programs in Canada. However, when professionals from two different disciplines collaborate, there is potential for challenges within educators’ relationship (Gibson and Pelletier,2011)in terms of defining professional boundaries, accommodating changes in professional identity, sharing common space and classroom resources, and understanding the 
roles of other partner within the educator team. Gibson and Pelletier (2011) argue that when one member has greater access to symbolic resources such as "pay and prestige" (p.3), there is the potential to dominate the other in the teaching team. Thus, collaboration between the professionals from two different disciplines is not an easy task and requires mutual understanding in decision making and working towards a common goal (Callaghan, 2012). Moreover, administrative support such as effective leadership by the principal is needed to reinforce the integration of the educator teams and requires a deeper understanding of the dynamics of the teaching team on the administrator's part(Gibson \& Pelletier, 2011). As principals involve in the process of FDK implementation, it is important to identify and acknowledge that a neutral and supportive atmosphere is required for the educator team to develop a collegial partnership through sharing their perspectives and practices. "Principals, as leaders of educational systems, must proceed in the spirit of success because seamless, coordinated and effective early learning is in the best interest of all children" (Cantalini-Williams \& Telfer, 2010). This emphasized the crucial role principals can play in successful implementation of the FDK program and call for attention at the policy level for identification of further leadership support needed. The following sections shed light on how my interest in the FDK program influenced my decision to undertake this study.

\section{My interest in the Full Day Kindergarten program}

As a former educator in Bangladesh, my interest in FDK implementation is specifically, due to its similarity with recently initiated universal pre-primary education program in Bangladesh encouraged me to pursue this study. In the following sections, I briefly discuss the universal pre-primary education program in Bangladesh and my involvement in it. 
In 2010, the government of Bangladesh introduced compulsory preprimary education for 4 and 5-year olds children as part of the National Education policy. The initial implementation process aimed to cover all government primary school throughout the country in collaboration with the non-government counterpart, and gradually expand throughout the country. The implementation process started with opening at least one pre-primary classroom adjacent to all government primary schools with play-based curriculum was planned for delivering by two teachers for a maximum of 20-30 children in the classroom (Ministry of Primary and Mass Education, 2008). Although, minimum education qualification for the government pre-primary teachers' required completion of Secondary School Certificate, most NGO teachers have lower educational qualification than required. The contents of the preprimary basic training program focused mostly on child care, child development, and preparation of learning materials. An ongoing professional development was also planned to deliver periodic refresher training (Directorate of Primary Education, 2012; Ministry of Primary and Mass Education, 2008). Both universal preprimary program in Bangladesh and FDK program in Ontario are similar in many ways, such as in terms of moving the early education intervention into the academic setting of school, introducing the play-based curriculum, education background, nature of training and remuneration of the teacher and early childhood educator, and challenges faced by the educators and administrators as they engaged in the implementation process.

My involvement in the universal pre-primary education program as part of my work with an international development organization and in the Pre-Primary Professional Development pilot initiative jointly fueled my interest to expand my knowledge and skills in the area of professional development of early childhood educators. A unique characteristic of the 
Ontario based project was to team the teachers and the early childhood educators together through a competency-based training developed based on the two-year diploma program for the early childhood educator in Canada. My involvement in the competency-based training was helpful for understanding how these individuals constructed their image of children, childhood as well as their own images as teachers, and early childhood educators. In addition, my own academic background and professional experience as a teacher and an early childhood professional was helpful for visualizing how my educational background, training, and professional experiences influence the way I interpret my role as an early childhood professional.

The findings of the proposed study have the potential to inform both FDK and the universal pre-primary education programs about how the knowledge, expertise and experience of each educator within teaching team can contribute towards high quality program delivery for children. Understanding the professional background of the educators is crucial to understand their roles in the FDK program, and understanding educators' role based on their lived experiences is instrumental to strengthen the partnerships between the members of the educators' team through reducing their experiences of challenge in the FDK program. The following section highlighted challenges that hindered the performance of the teaching team.

\section{Statement of Problem}

Introducing the teaching team through the implementation of FDK program emphasized the importance of delivering the early learning intervention by qualified educators in a collaborative manner (Gananathan, 2011). However, recent study findings (Ministry of Education, 2013) suggested that in many cases, members of the teaching team were not capitalizing on the collective expertise of their professions. Both Gananathan (2011) and Ministry of Education (2013) highlight that the lack of understanding among the boards, 
administrators, and principals about ECEs’ training, knowledge and skills regarding child development resulted in lack of direction in defining the roles and responsibilities of the ECEs.

Although some educators and administrators collaborated to define the role and responsibilities within the educational setting of the school, many others raised their concerns that defining the roles and responsibilities further is crucial to ensure that children benefit the most from FDK program (Ministry of Education, 2013; Tozer, 2012). Participants interviewed in Gananathan (2011) study raised their concerns "about lack of understanding of their role in the school system, and their frustrations about being constrained by school policies that prevent them from responding to their young students needs in caring and nurturing ways. This suggests that the lack of understanding about the ECEs' academic and professional experiences among the school communities contributed towards misunderstanding and undermining their ability to work with young children, and limited them to practice their ECE training in the FDK classroom. One such example is evident in the findings from the Gananathan (2011) study that revealed ECEs' frustration regarding their inability to use their knowledge of child development in the educational context of FDK. The study (Gananathan, 2011) participants suggested that schools' "no touch policy" (p. 38) prevented them from establishing a caring and nurturing relationship with the children and raised their concerns about the impact of such school's policy on children's social and emotional development. For example, one of the study participants expressed her frustration, and informed the researcher that not responding to a child's emotions in a "caring and nurturing ways” (p.39) due to school's "no touch policy” (p.38) resulted in difficulties in self-regulating on the child's part. Given the fact that ECEs are trained to respond to their young children's needs for proximity, or to meet the demand of a particular situation in a caring and nurturing way, in this particular situation, they were following the policy of the school 
(Gananathan, 2011). Although, this is just one example illustrating how lack of understanding of ECEs' roles in the school system prevents them to practice their training knowledge in the FDK classroom, greater understanding is needed to avoid repetition of similar incident and to strengthen support for ECEs so that they can practice their professional expertise in the FDK classroom.

Moreover, a lack of understanding among administrators and teachers about ECES' roles and responsibilities may not be the only factor affecting the performance of the teaching team. Differences in professional status in relation to salary, education background, working condition and status among the educators were also identified as negative factors hindering the team performance (Gibson \& Pelletier, 2011). In addition, the lead responsibility of the OCTs in relation to instruction, classroom management, and assessment in the classroom(Ministry of Education, 2010) placed the ECEs in a "precarious position having to negotiate their roles and responsibilities with their teaching partner in an attempt to cooperate” (Gananathan, 2011,p.43). This correlates with study findings regarding ECEs' concerns about persistence of hierarchy and discrepancy in status among some ECEs working alongside OCTs in the FDK classroom (Corter, Janmohamed \& Pelletier, 2012; Gibson \& Pelletier, 2011). Issues related to OCTs having more power and higher salary compared to ECEs continued to dominate the discussion about the performance of teaching team in the FDK program (Corter, et. al; Gibson \& Pelletier, 2011; Pelletier, 2014).

Many ECEs found it challenging to partner with someone who shared almost the same responsibility whereas received better pay and held higher authority within the teaching team. According to Gibson and Pelletier(2011) indicated the detrimental effect of this hierarchical structure on the quality of team teaching, and emphasized the need for further research to see 
how ECEs preserve their identity in a working condition where the OCTs are more privileged in relation to their education, better pay, and orientation within the educational environment of the school. Within the scope of current study, exploring the perceptions of ECEs about their roles and responsibilities based on their lived experiences provided opportunity to explore how ECEs' experience of such hierarchy influence the construction of their roles within the FDK program. In addition, use of post-colonial theory and Michel Foucault's post-structural concept of "power/knowledge" supported to move beyond and deconstruct the traditional notion of ECE role within the teaching team (Foucault \& Gordon, 1080).

\section{Purpose of the Study}

The purpose of this study was to understand ECEs' perceptions of their roles and responsibilities in the FDK program. In addition, this study explored the experiences, successes, and challenges faced by the ECEs in the FDK program. A qualitative research approach was chosen to understand ECEs' perception of their roles and responsibilities based on their lived experiences. Using the post-colonial theory and Foucault's post-structural concept of "power/knowledge" the focus was to understand ECEs perceptions from their position and rather than taking an expert position. Understanding ECEs’ perceptions of their roles and responsibilities was important to investigate how ECEs shape their perceptions based on their lived experiences in the FDK program. Such an understanding may inform the FDK implementation process to accelerate the desire for more effective integration of the teaching team. 


\section{Research Questions}

What are early childhood educators' perceptions of their roles and responsibilities in the full day kindergarten program?

Below are some examples of sub-questions (attached as appendix A and B) that were developed in order to inform the broader research question.

- $\quad$ Describe your role in the FDK.

- How is your role similar or different compare to a teacher's role in the classroom?

- Describe your experiences around the implementation of the FDK program.

- Describe your experience in the FDK classroom.

- $\quad$ Describe what you think your role in the FDK should be.

- Describe what kind of support do you get as an ECE to perform your role as a member of the teaching team. 


\section{Theoretical Framework}

Findings from the literature highlighted that despite many positive experiences, early childhood educators' (ECEs) continued to face challenges in terms of performing their roles and responsibilities in the FDK program (see Gananathan, 2011; Gibson \& Pelletier, 2011; Ministry of Education, 2013). The literature also highlighted the differences in educators’ professional status (in terms of educational background, salary, and working conditions) indicating that teachers appear more powerful compared to ECEs in the dominant discourse on educators' roles in the teaching team (Gibson \& Pelletier, 2011). Such findings from the literature necessitate a theoretical framework for this study that would allow me to look beyond the taken for granted assumptions about ECEs' images/identities in the FDK program, as well as, in the broader education discourse. A theoretical framework that would support an understanding the way ECEs' roles in the FDK program are described in the ongoing discourse required an examination of the power dynamics that exist between the members of the teaching team. Such understanding requires problematization of complex and uncertain aspects of ECEs’ lived experiences in the FDK program in order to develop a new perspective. To achieve this aim, I utilize post-colonial concepts, and Michel Foucault’s post-structural concept of "power/knowledge” to guide the framework of this study (Bhabha, 1994, Foucault, 1980; Said, 1979).

Post-colonial perspective supports understanding of ECEs’ perception of their roles and responsibilities based on their lived experiences in the FDK classroom. A post-colonial lens also helps to look beyond ECEs' taken for granted images portrayed in the society. Post-colonialism is not only limited to the study of colonial empire and race, rather it is more concerned with searching an activist position seeking social change (Viruru, 2005). This suggests that post- 
colonial perspectives offers ways to unmask the realities, resist any form power dynamics or oppression, and look for new possibilities.

The process of unmasking ECEs' reality in the FDK context was not an easy task and involved a shift in one's position, because, without being in their position it was hard to understand how ECEs construct their perceptions based on their lived experiences. Nieuwenhuys (2013) argues post-colonialism demanded elimination of looking at the world from a high-level position and adoption of marginalized position. The author further argues that without challenging the existing binaries it would not be possible to unmask the reality thus, postcolonialism is more than a practice of shifting position to "better grasp the world as seen by those whose voices are seldom heard” (Nieuwenhuys, 2013, p.7). I recognized that ECEs' perceptions of their roles and responsibilities can be better portrayed if done by the ECEs themselves rather than positioned from the voice of an expert. Thus, the choice of post-colonial lens supports to change my position as a student researcher through my effort to understand ECEs' lived experiences of their roles and responsibilities from their own perspectives.

\section{Post-colonial theory}

Postcolonial theories highlight the relationship between the binary positions such as colonizer and colonized; however, this relationship is not like any other relationship rather " one in which an entire society is robbed of its historical line of development, externally manipulated and transformed according to the needs and interests of colonial rulers (Osterhammel, 2005, p.15). Post-colonialism refers to the historical period of "imperialism” (Childs \& Williams, 1997, p. 21) and the Western attempt to rule the world over many centuries in order to "essentialize the diverse societies into one universal form” (Viruru, 2005, p.8). Post-colonialism indicates the end of colonial era and the beginning of historical moment that offers new understanding of the 
colonial periods, and devising ways for further analysis and practice of how individuals are "othered” (Viruru, 2005). Similarly, the use of post-colonial theory as a guiding framework, helps to understand how ECEs are expected to assimilate into the school culture, and is "othered" in the process of assimilation.

In his book, Orientalism, Said (1979) discusses how the dominant West perceives and represents the East based on assumptions and referred them as "Other" (Childs \& Williams, 1997, p.100). According to Said (1979), “Orientalism as a Western style for dominating, restructuring, and having authority over the Orient” (p. 3). This suggests how the dominant West exercises it power over the less powerful Eastern part of the world. The Western society draws conclusion about the "orient" without knowing or actually being in the position of the "orient" (Childs \& Williams, 1997). Said's lens of Orientalism was helpful to understand how ECEs are perceived as "Orient” within the academic environment of school due to their different knowledge and professional background. Within the school culture their roles are interpreted differently without knowing much about their professional practice and expertise.

For example, in the Gananathan (2010) study participants expressed how they were expected to follow the school's no touch policy, and were "othered" in the process of "schoolification” of their professional knowledge and practice. They reported that the school's "no touch" policy prevented them to respond to their children's needs in a nurturing and caring way which often involves touching. Thus, in the school environment ECEs had no option but to comply with the "no touch" policy of the school.

Said uses the term "Other" to discuss how the dominant West (self) constructs the nonWestern image of the (other) in order to gain authority over the Orient (Said, 1979; Childs \& Williams, 1997). This suggests that the people of the West treated the Orient as something 
unfamiliar and different who are incapable of representing themselves, and decide to speak, write, and act on their behalf-about them, for them without consulting them” (Childs \& Williams, 1997). Said (1979) argues,

For Orientalism was ultimately a political vision of reality whose structure promoted the difference between the familiar (Europe, the West, "us”) and the strange (the Orient, the East, "them"). This vision in a sense created and then served the two worlds thus conceived. Orientals lived in their world, "we” lived in ours. The vision and material reality propped each other up, kept each other going (p.43-44).

This shows that the way the West produced knowledge about the East is not innocent and reflected certain interests such as hiding the flaws of their own culture or the inequity in the society. Perhaps, the dominant culture creates the "Other” to justify their colonized authority over the colonizers. In the context of the current study, Said's concept of “Other” was useful to understand how the ECE role was perceived and represented within the dominant discourse on the teaching team.

In contrast to Said, another migrant intellectual Homi Bhabha discusses that the postcolonial discourse focuses too much on the concept of fixity of the binary positions, rather than accepting the difference (Bhabha, 1994). However, Bhabha acknowledges the influence of Orientalism in initiating his own scholarly project in the field of postcolonial studies and uses Said as a point of departure, and adopts a different approach towards colonial discourse. Bhabha's argues Said's approach to colonial discourse as involving over simplified binaries like East and West, colonized and colonizers and seeks to revise and extend on other aspects of Orientalism. Such as, Said discusses how colonizers exercised their power over the colonized people, viewed them as different and unfamiliar entities, and labeled them as "Other”. Bhabha extends on these binaries and uses the lens of colonial subjectification to examine the relationship between the colonizers and the colonized people. Bhabha introduces a set of 
challenging concepts that are at the core of postcolonial theory for example, "hybridity, mimicry, differences, third space, and ambivalence” (Bhabha, 1994). Although, these concepts are helpful in understanding the complex cultural contact and interaction that took place in the colonial period, my study focuses on Bhabha’s concepts of "hybridity” and "third space."

In his book Location of Culture, Bhabha (1994) says, "we find ourselves in the moment of transit where space and time cross to produce complex figures of difference and identity, past and present, inside and outside, inclusion and exclusion” (p.1). This highlights the complex process through which ECEs shape their perceptions of their roles and responsibilities during their transitions in the FDK program. This also suggests how the taken for granted assumptions about the ECE role contribute towards exclusion and inclusion of ECEs' distinct knowledge and professional experiences in defining their new roles and responsibilities in the FDK program.

However, Bhabha (1994)further notes,

The representation of difference must not be hastily read as the reflection of pre-given ethnic or cultural traits set in the fixed tablet of tradition. The social articulation of difference, from the minority perspectives, is a complex, on-going negotiation that seeks to authorize cultural hybridities that emerge in moments of historical transformation. (p. 2)

In the context of this study, Bhabha's such idea on identity formation helps to destabilize the taken for granted assumptions about ECEs' roles, and emphasized the need for considering ECEs' lived experiences to better understand their perceptions of their roles and responsibilities in the FDK program. Considering ECEs' lived experiences allows space for ECEs to share their experiences of identity negotiation with their teaching partners. This also allows ECEs to raise their voice and exercise their power against any dominant power existing within the teaching team. ECEs' such exercise of power in its productive form has the potential to create space for reflective practice. Educators in their collaborative relationship can use this space to negotiate 
their new identities through inquiry and reflective dialogue (Ontario College of Teachers, 2012). Thus, Bhabha introduces a series of concepts to challenge the traditional way of looking at the world through the lens of "self and other", and to focus on the complex process of hybridization (Bhabha, 1994; Huddart, 2006).

Bhabha introduces the concept hybridity in order to destabilize the colonial fixity and discusses that hybridity is a process which allows different identities to come together to interact with each other (Bhabha, 1994). However, this process coming together is not an easy task and introduced to increased tension. This increase in tension is required to destabilize the colonial rigidity and to challenge the colonial authority (Ramone, 2011). In 1990, in an interview with Jonathan Rutherford Bhabha discusses,

the importance of hybridity is that it bears the traces of those feelings and practices which inform it, just like translation, so that hybridity puts together them the the traces of certain other meanings, or discourses. It does not gives them the authority of being prior in the sense of original...the process of cultural hybridity gives rise to something different, something new and unrecognisable, a new area of negotiation of meaning and representation. (p.211)

This indicates how a translated text embodies both original language as well as the translated language. Similarly, when individual migrates from one culture to another become a translated individual bearing traces of both cultures. Thus, hybridity as an ongoing process refers to the mixed-ness in identities during cultural transformation (Huddart, 2006).

Bhabha discussed that hybridization takes place in an "in-between" space or liminal space. This is an ambivalent space where the hybrid identity and new culture form. Bhabha argues that this transformation is not an easy task and involves negotiation of identities that may cause conflict and antagonism (Bhabha, 1994). Evidence from the review of the literature also 
highlighted similar conflict and antagonism as they negotiate their new roles in the FDK program.

Postcolonial theories allow individuals to view the situation from the position of being marginalized or oppressed providing opportunity to challenge the inequality in the society (Nieuwenhuys, 2013). Post-colonial thinkers offer strategies to study the oppressed, search for new possibilities, resist various forms of binaries and control in the society, and open up spaces for production of new knowledge by considering the views and experiences of the oppressed or marginalized people (Childs \& Williams, 1997; Nieuwenhuys, 2013; Viruru, 2005). Thus, postcolonialism challenges the Eurocentric ways of looking at the world in order to destabilize the dependence on the "concept of fixity in the ideological construction of otherness" (Bhabha, 1994, p.66).

The choice of a post-colonial lens is helpful to understand the troubling aspects of performing the ECE role in the FDK classroom, and ECEs relationships with the children and their teaching partner. It offers ways to deconstruct issues, ideas or themes from a new perspective. Deconstructing through the lens of post-colonial theory creates an opportunity to destabilize ways by which ECEs' roles and responsibilities are perceived, understood, and known within the academic environment of schools. The use of post-colonial theory, thus, creates spaces for ECEs to speak for themselves and to contribute to the ongoing discourse on ECEs' roles in the FDK classroom, and, offer ways to balance the imbalance between ECE and teacher roles, and education and care divide. 


\section{Foucault’s post-structural concept of “power/knowledge”}

The review of the literature highlighted hierarchy in educators' relationship in terms of differences in professional status, such as education background, salary, working condition etc., and indicated, power imbalance within the teaching team (Gibson \& Pelletier, 2011). This suggests that in the dominant discourse on educators' roles in the teaching team, teachers are represented as more powerful compare to ECEs working in the FDK program. Such findings encourage me to consider Michel Foucault’s concept of “power/knowledge” to develop my theoretical framework (Foucault \& Gordon, 1980). In his book Power/Knowledge Selected Interviews \& Other Writings Michel Foucault notes,

By truth, I do not mean the ensemble of truths which are to be to be discovered and accepted...truth is to be understood as a system of ordered procedures for the production, regulation, distribution, circulation and operation of statements. Truth is linked in a circular relation with systems of power which produces and sustain it (Foucault \& Gordon, 1980, p.133).

Here Foucault draws our attention to focus on the complex relationship between truth and power that governs the ongoing discourse in the society, and offers multiple perspectives to observe the complex and changing nature of truth. Foucault challenged presence of absolute truth and believed that truth is ever changing depending on different time points and places (Mac Naughton, 2005). Acknowledging that truth is complex allows different thought processes that ultimately turn into developing alternate viewpoints to problematize any research inquiry. The post-structural lens allows a researcher to view a research problem from multiple perspectives and for different issues to emerge that may have been remained unobserved in other neater approaches to research (Gibson, 2013).

Similarly, in the field of early childhood, post-structuralism encourages early childhood educators to become "critically reflective educators" to understand how power in its oppressive 
form operates in between people in educational settings, and then "use their analysis to work against that oppression and inequity” (Mac Naughton, 2005, p.7). Such reflective practice allows educators to take an activist position and be in charge of their own learning and meaning making about their identities in order to transform their understandings and practices (Mac Naughton, 2005).

Foucault was widely regarded because of his work that explores "relationships between power, discipline, knowledge and our bodies” (Mac Naughton, 2005, p. 5). In particular, his post-structural theoretical concept of "power/knowledge” (Gibson, 2013, p.61) focuses on the intimate relationship between the two elements and highlights "one does not occur without other; knowledge gives rise to power, but it is also produced by the operation of power” (Childs \& Williams, 1997; Gibson, 2013). Drawing on Foucault’s concept of “power/knowledge” in this study was instrumental to rethink the existing relation of power between the members of the teaching team. To view this relationship of power with alternative perspectives has the potential to destabilize the way it is described in the dominant discourse.

According to Foucault, power and knowledge are tied into a complex relationship (Foucault \& Gordon, 1980) and “exercise of power itself creates and causes to emerge new object of knowledge and accumulate new bodies of information” (p.51). The mechanism of power functions in our everyday interactions with people in society. Foucault discusses, Power must be analyzed as something which circulates, or rather as something which only functions in the form of a chain. It is never localized here or there, never in anybody's hands, never appropriate as a commodity or piece of wealth. Power is employed and exercised through a net-link organization. And not only do individuals circulate between its threads; they are always in the position of simultaneously undergoing and exercising this power. (Foucault\& Gordon, 1980, p.98) 
As such, Foucault suggests that power is not something that belongs to individuals or institutions in order to use oppressively against others; neither is it a plain relationship between the oppressed and the oppressor. Rather, power is inherently webbed into all interactions.

As power exists everywhere in all relationships, and circulates with and through discourse (Caldwell, 2007) it must be explored as a chain or network within which "individuals are the vehicle" and "not its point of application" (Foucault\& Gordon, p. 98). This indicates that in a power/knowledge relationship the individual as the subject has the capacity to exercise power to change the way identities are produced in the discourse (Gibson, 2013). As well, “discourses become more or less powerful at different points in time, dependent on the conditions” (Gibson, 2013, p.70).

This means that power has the capacity to define a particular way in which an individual should behave or perform his or her role. Additionally, power an individual exercises has the capacity to influence the dominant discourse leading to change in how individuals behave or perform their roles. In this manner, "identities shift and emerge, depending on the power/knowledge relationship discourses that are in circulation, and come together in different ways, at different moments” (Gibson, 2013, p. 70). It is, therefore, important to critically examine the taken for granted assumptions about individual identities and roles to understand how the dominant discourse makes an individual powerful or powerless based on the way his/her subjectivity is formed.

In the context of the current study, the review of the literature highlights that in the dominant discourse, teachers are portrayed as more powerful compared to ECEs working in the FDK program when considering educational background, salary, working conditions etc. (Gibson \& Pelletier, 2011). Knowledge of curriculum and work experience in an academic 
school environment allows teachers to sustain their power within the teaching team and in the public school sphere. Such differences in educators’ professional status create hierarchy within the teaching team, and highlight the detrimental effects of this hierarchical structure on the quality of team teaching in the FDK classroom (Ministry of Education, 2013; Gibson \& Pelletier, 2011).

While Gibson (2013) states that "power is understood both repressive and at the same time productive” (p. 71), Foucault’s lens of power/knowledge in relationships is helpful to understand how ECEs working in the FDK program can preserve their identities within a hierarchical structure: "If I feel the truth about myself it is in part that I am constituted as subject across a number of power relations which are exercised over me and which I exercised others” (Foucault, 1988, p.39). Hence, it is worth considering how ECEs contribute to the dominant discourse on roles of ECEs and if they are able to exercise their power to further the knowledge about their roles in the FDK program.

To develop a theoretical framework for this study, I introduced Michel Foucault, Edward Said and Homi Bhabha and combined key concepts like, “Other”, "hybridity,” "third space” and "power/knowledge”. All three theorists acknowledge the presence of binaries identities such as self and other however, use this as a point of departure to introduce a shift in our traditional way of viewing and thinking about the world through examining the relationships between these two elements and accepting differences in the process to move beyond rigid and fixed boundaries. The combination of the post-colonial and post-structural was instrumental to develop a new perspective and to unmask the reality of the ECEs working in the FDK classroom, to understand how they shape their perception of their roles and responsibilities based on their lived experiences when negotiating their new identities within the teaching team. 


\section{Literature Review}

Several ideas related to early childhood educators' (ECEs) perceptions of their roles and responsibilities in the classroom emerged from the review of the literature, and provided a deeper understanding of how ECEs in different contexts experienced and expressed their roles and responsibilities as educators. Defining the roles and responsibilities of the ECEs has always been a challenge because of their multifaceted role. Despite 150 years of significant history of childcare, professionalizing the field has been formally initiated recently. The childcare sector in Canada started in mid-nineteenth century by "educational, philanthropic, or religious organizations, often by prominent women” (Friendly \& Prentice, 2009, p.73)as a voluntary initiative. Similarly, rooted in social reform, Canadian kindergarten started in early nineteenth century "based on the emerging ideas of early leaning”(Friendly \& Prentice, 2009, p.72), but officially acknowledged by the Ontario government in 1885,much earlier than formal childcare. In 1946, after World War II, Canada’s first provincial child care legislation the Day Nurseries Act formally introduced childcare centers and early childhood educators (ECEs) in the public sector.

Despite Canada’s long history of childcare, "considering the service as a profession is still undecided” (Martin, Meyer, Jones, Nelson \& Ting, 2010). The diversity of the language in early childhood field such as Early Childhood Education, Child Care, Preschool Education, Early Education, Child Development etc. contributed towards defining professionalism in the field and finding a universal language for the frontline professionals, although it has also contributed inconsistent perspectives. A qualitative study (Harwood, Klopper, Osanyin \& Vanderlee, 2013) involving 25 ECEs from Ontario, Nigeria and South Africa suggested that, "ECEs have a long history of devaluating their own professional identities" 
(p. 5). Their diverse roles as caregivers, babysitters, teachers, and early childhood educators made it even harder to define them under any fixed professional category. The study (Harwood et al., 2013) participants were given a platform to spell out the essential aspects of their professionalism and the philosophy that influence their perceptions of their roles as ECEs. Another study (Vanderlee, Youmans, Peter \& Eastbrook, 2012) aimed to evaluate the full day early learning program in Ontario highlighted the following:

The duties associated with the teacher's roles and responsibilities are enshrined in the legislation and have been in practice for years contributing to a generally accepted and shared image of the teacher in the public school sphere. What is not clear is an explicit image that includes the duties, roles, and responsibilities of the ECE in the same school sphere. (p. 86)

This suggests although, ECEs' roles and responsibilities are enshrined in the College of ECEs Standards of Practice however, a clearer understanding of ECEs' roles and responsibilities is required within the teaching team and in the greater school community. The authors (Vanderlee et al., 2012) argue the legislative statement claiming that the teaching team has a duty to cooperate is open to the interpretation of the school board because of ECEs' unclear role in the FDK program. According to Vanderlee et al. (2012),it is the responsibility of the Ministry that the professional image of the ECE is clearly articulated in terms of their shared responsibilities within the teaching team, in the classroom, communicating with parents, and in supporting children's learning and development. This correlates with Barnett's (2004) study that suggests educational background, professional development and certification/regulation, salary and benefits, and pre-service training are important considerations for the policy makers and educators while professionalizing the sector. Moreover, individuals need to have knowledge on children's development and learning, ability to build relationship with families and the 
community, and to learn in an ongoing basis based on observing, documenting and assessing children learning and development to become professionals (Martin et al., 2010).

Vanderlee et al. (2012) further argue that lack of attention in the area of defining ECEs' roles and responsibility may lead to open interpretation of the image of the ECE among the unions, teachers' federation, school board, principals and teachers thus, may lead many ECEs to feel or act as assistants in the FDK classroom. This was evident in the study findings (Gananathan, 2011; Ministry of Education, 2013) where lack of understanding about ECEs' knowledge and professional background among the school administrators caused lack of direction in defining their roles and responsibilities. In their concluding thoughts, Vanderlee et al. (2012) recommend that in order to have promising effect of FDK program, the image of the ECE needs to be a priority issue on the agenda of the Ministry of Education, because, ECEs' perceptions of the external construction of their roles shifted from the way they perceived it even a decade ago. More recently, they appeared to be more critical in evaluating and reflecting on how the public/policy framework positioned their roles (Harwood et al., 2013). This was evident in the Romain \& Petersen (2012) and Harwood et al. (2013) study where the participants considered themselves as professionals, and defined their role as having specific knowledge about children's learning and development in the early years, play based teaching methods, and designing activities that meet children's individual needs. They viewed their role as qualified professionals in the classroom, who can assist not only the children in their learning process but also, assist the teachers in deciding the best intervention for the children. This highlights the complementary roles that ECEs can perform within the academic environment of school. The sense of commitment and enjoyment of work seemed to have a strong correlation with the ECEs' feeling of being professionals (Martin, Meyer, Jones, Nelson \& Ting, 2010). 
Evidence from the literature illustrated that when performing an important and complex role, ECEs seek for clearer definition of their roles and responsibility in order to have a professional recognition of their work. Harwood et al.(2013) stated, "perhaps professionalism within early years field is resistant to dichotomized ideas of care and education”(p.10). This highlights the holistic approach of early childhood profession where establishing a responsive relationship with the children is fundamental for creating a stimulating learning environment that encourages children to thrive into their full potential. In the book Intersections: Feminism/Early Childhood Hauser \& Jipson (1998) argue, "in the field of early childhood education, however, it is impossible to tease apart the twin strands of education and care, especially with the young children” (p.53). Creating a caring and encouraging environment is necessary for children to feel safe to actively participate in their own learning and, therefore, it is hard to separate care and education in the field of early childhood. It is also important to note that child development knowledge, skills and parents engagements techniques demonstrated by ECEs are the basis of FDK (Gananathan, 2011), and the significant role they play in young children learning is crucial for children's future success in school.

Research showed that ECEs' nurturing and caring relationship with their children are core to their ECE profession (Gananathan, 2011).Their enjoyment for the children, their desire to support young children and their families, and a passion for teaching inspired them to become ECEs and pursue their career in this field (Harwood et al., 2013). The study participants viewed their roles as passionate educators who are motivated to pursue an early childhood educator's profession. The participants interviewed highlighted that the children in the classroom, especially children with learning difficulties, were the source of their motivation and passion to continue as ECEs. They found themselves capable of supporting these children to advance in their learning 
process and found it rewarding (Harwood et al., 2013). Thus, the passion for working with children and their families has an impact on why they choose this profession, which ultimately influences how they perceive their roles. This correlates with the findings from the current study that depicted participants' interest to work with young children motivated them to continue their work in the field of early childhood.

Moreover, ECEs reported that their love and the emotional support they provide to the children are the basis for establishing a respectful and mutual relationship with the children (Harwood et. al, 2013). This correlates with Nodding’s (1984) concept of mutuality where caring teaching-learning relationship takes place between educators and children in a give-and-take manner, and the response of the children to their educator's care is visible. ECEs in the study (Harwood et al., 2013) viewed themselves as responsive educators supporting children’s learning with care so that the children can grow up as socially and academically successful adults. Their own sense of accomplishment was found to be associated with the successes of the children. They felt the nurturing and caring relationships they establish with children in the early years, support the children in learning and acquiring skills necessary for future success in school and beyond.

Evidence from the literature suggested that a better understanding of ECEs’ diverse role is much needed for the development of a supportive and responsive learning environment for the children. Support from the school and in-depth understanding of the educators' role is required to ensure that children benefit the most from the early intervention programs. Harwood et al. (2013) study depicted similar suggestions where ECEs recognized the embedded nature of their roles across several subsystems of the ecological system of child development (Bronfenbrenner, as cited in Harwood et al., 2013), and supports required to function within each subsystem. For 
example, the study (Harwood et al., 2013) participants discussed classroom as the micro system,and mentioned the support needed for resource mobilization and establishing relationship among the team members and the families. In the exo-system they expressed their desire for integrated family services to intertwine families in children's schooling process. ECEs identified the support required at the macro level as "resources and financial support, setting standards of quality, providing universal access to programs and educational opportunities for them and devising policies to support the early childhood field” (Harwood et al., 2013, p. 10). This also correlated with Gananathan’s (2011) and Pelletier’s (2012) studies where the participants interviewed described the positive experiences they encountered while interacting across different systems of FDK program model, such as establishing strong relationships with the teachers and administrators of the school, supporting children in the classroom and developing relationships with parents and families. Research illustrates when support is offered at each level, educators excel in their performance to deliver a high-quality program.

Although, the FDK program aims for high quality play-based program delivery through the teaching team (Pelletier, 2014), hierarchy and power imbalance within the teaching team have been highlighted as “greatest challenges of the FDK model” (Pelletier 2014, p. 17). Hierarchy in salary, status, educational background, lead responsibility and working condition dichotomized the roles of the educator team, and hindering their performance (Gibson \&Pelletier, 2011; Gananathan, 2011). Study findings looking at the perceptions of the staffs in the FDK classroom highlighted the power imbalance and inequalities in working conditions among the members of the teaching team (Pelletier 2013). Lack of understanding and guideline about the roles and responsibilities of the ECEs often positioned them as assistants in the FDK classroom. Findings revealed teachers in the decision-making role in terms of sharing 
responsibilities and ECEs to collaborate with the teacher (Vanderlee, Youmans, Peter \& Estabrook, 2012). Teachers have more power over assessment, long-term planning, and family communication than the ECEs, and ECEs' role was to follow the teachers' lead (Pelletier, 2012; Vanderlee et al. 2012). In contrast, the education act (2014) clearly outlines that both educators have a "duty to cooperate" (Government of Ontario, 2014, Part-X, section, 264.1) in delivering the FDK program. It is crucial to investigate how this policy direction was interpreted within the context of this study.

The Pelletier (2012) and Vanderlee et al. (2012) studies’ findings portrayed teachers as authoritative individuals in its traditional sense. Langford (2010) defined authoritative individual in its traditional sense as "an individual person with authority has strong influence, power, and control over others who must obey, and this authority can be justified on the basis of institutional position or disciplinary expertise alone” (p. 293). The traditional definition of authority emphasized more on power, hierarchy and control rather than mutual growth and development through collaboration and exchange of knowledge and expertise. In connection with this traditional definition, ECEs lack in power and authority throughout the history, which was also evident in the findings of studies conducted in the FDK classrooms. This power imbalance between the members of the teaching team raised concerns among the FDK parents regarding its potential influence on children's experiences in the classroom (Ministry of Education, 2013; Vanderlee et al., 2012). As FDK children spent most of the time of their day with the members of the educator team, the relationship between these two members is crucial for ensuring responsive and joyful environment to encourage children exploration through play-based learning. According to Langford (2010) ECEs should practice their authority to eliminate inequalities in the society and to take actions in order to promote social goods. Langford (2010) 
further discusses "early childhood educators have authority when they are knowledgeable. Their knowledge consists of information, understanding, or, skills acquired through learning and experiences” (p. 298). This suggests that ECEs should practice their authority through implementing their expertise for the betterment of children and their families. This authority of ECEs would not reflect the traditional notion of authority rather, would be based on a "respectful and trusting relationship” (Langford, 2010, p. 298) with the people who bring different perspectives to their professional practices, and are part of ECEs' everyday lives, such as children, parents and colleagues. However, Langford (2010) cautions that continuously defining and regulating ECEs through the external "top-down expert systems” (p. 302) may prevent the ECE to recognize the potential of their own authority. This correlates with post-colonial notion of "externally manipulated and transformed according to the needs and interest of colonial rulers” (Osterhammel, 2005, p.15). This suggests that ECEs need to have authority to define and articulate their roles and responsibilities based on their lived experiences.

ECEs' ability to be resilient, and awareness to articulate roles and responsibilities, and their interests for acquiring professional knowledge and skills may influence their sense of agency. In the Harwood et al. (2013) study, ECEs demonstrated their sense of resiliency through considering workplace challenges as opportunities for their own growth and development. From post-colonial perspective, this suggests ECEs' ability to fight back against the odds and search for new possibilities. For example, participants interviewed expressed their strong belief that they learn from their mistakes, and they appreciate feedback from others', which enables them to improve their teaching and caring abilities. They also expressed their desire to influence societal, systemic, or educational change, and demonstrate their sense of authority to promote social goods (Langford, 2010). Thus, ECEs' demonstrated their self-awareness, which is an important 
aspect of personal growth that helped them to reach out for seeking support from other people and developing integrity. Educators with integrity can avoid the binaries of personal self and professional self and are able to think and act in an integrated way that matches with their beliefs and values (Harwood et al., 2013). However, Romain \& Petersen (2012) indicate that in FDK program ECEs need support to handle the structural changes and team teaching approach in order to perform even better. Teaching the new curriculum in an entirely new program requires significant support because this is the first time when ECEs are exposed to the team-teaching approach, in addition to sharing classroom space and resources with another professional. Tozer (2012) suggests that despite recognizing the importance of the effect of a collaborative relationship on students' outcome, ECEs and other team members were unsure of the strategy to form such collaboration because of lack of directions in defining their roles and responsibilities. As a result, there were few instances where ECEs faced non-cooperation in the FDK classrooms and lack of trusting relationship with teachers in the classroom. However, there were other instances where the ECEs managed to overcome these challenges caused due to unclear expectations and role confusion (Tozer, 2012). For example, two of the ECEs who participated in the study working in the FDK reported that they worked out their roles in the FDK classrooms in order to perform successfully as team members. They were aware of the transition that the teachers were experiencing, and the fact that before FDK, the teachers were solely responsible for the kindergarten classroom for many years, and it would take time to build a trusting relationship. ECEs reported that they were respectful and empathetic of the teachers' position and regulated their behavior to work collaboratively with the teachers. This suggests ECEs encompass their professional values and beliefs (College of Early Childhood Educator, 2011) as they perform their complementary roles within the teaching team. In addition, the ECEs 
also pointed out that the opportunity for displaying their knowledge and skills in the classroom contributed positively in forming the team relationship. The positive attitude of the ECEs towards the collaborative work in FDK and their awareness of the importance of time in building a trusting relationship with the teachers demonstrated their ability of becoming successful team members (Tozer, 2012).

In addition, ECEs demonstrated their ability to identify and expressed their needs for training in order to provide quality-learning environment for children (Harwood et. al, 2013). For example, ECEs interviewed in the Toronto First Duty project, which was piloted to see the effectiveness of a universal integrated model, identified that there were differences in the training of teachers and ECEs, and neither type of training alone was sufficient to operate the program (Corter, Janmohamed, \& Pelletier, 2012). This indicates the importance of combining the expertise of both educators to deliver the FDK program, and coincides with Tozer (2012) that the skills and capacities ECEs bring to the kindergarten complement teachers' skills and capacities.

However, Tozer (2012) further argues that ECEs working in the FDK program had no training on literacy and instructions skills and, therefore, were unable to provide reading support to the children. ECEs interviewed expressed their concern that having the basic literacy instruction skills would be beneficial for the children. Some, ECEs received support from the teachers to acquire and practice literacy instruction skills with the children (Corter et al., 2012). Furthermore, ECEs thought that teachers have different kinds of knowledge and skills and they could learn from them, which portrayed reciprocal respect for each other's expertise. This suggests educators' initiatives for self directed learning through collaborative partnership which is also highlighted in Foundations of Practice (Ontario College of Teacher, 2012). However, Gibson and Pelletier (2011) study participants emphasized the need for joint professional training 
and planning time in order to strengthen the partnership of the educator team. Gibson and Pelletier (2011) argues that lack of joint planning time may lead the teacher planning classroom activities without discussing with the ECE, and may force ECEs to take the assistants' role in the classroom.

The literature review identifies ECEs'self-awareness about their own strengths and limitations, their attitude and openness to accommodate them within the ongoing change processes which reflect their ECE training and professional aspects of their roles. Despite the challenges of the new curriculum, structural change, lack of understanding of their new roles and difficulties in collaborating with teachers, ECEs value what they do for the children and their families in the FDK program. However, any of the literature did not reflect directly how ECEs perceive their roles and responsibilities within the FDK program. It was challenging to find literature that specifically aimed towards exploring ECEs perceptions of their roles and responsibilities. Most studies focused on the implementation and impact of the FDK program on different areas of early childhood care and education such as children, new teaching team and parents, and families. As the childcare system in Ontario was transitioning to the educational context of FDK program, therefore, recognizing ECEs’ perceptions of their roles and responsibilities is crucial for successful implementation of the teaching team. However, the review of the literature indicates gap in this area of research and emphasizes the need for further study. 


\section{Methodology}

In order to understand ECEs' perceptions of their roles and responsibilities in the full day kindergarten (FDK) program, I chose a research methodology that would allow me to gather information based on ECEs' lived experiences in the FDK program. The use of post-colonial theory and Foucault's post-structural concept of "power/knowledge” as a guiding theoretical framework for this study required a selection of methods that enabled ECEs' to voice their experience and their perceptions of their roles in FDK, and supported me to answer my research questions based on their shared experiences. As a result, I chose a research approach that allows acquiring information from the standpoint ECEs working in the FDK context in order to transform my new knowledge into data gathered following a scientific rigorous process.

\section{Research design}

A qualitative research approach was proposed for this study because of its exploratory nature that investigates phenomena with an open mind rather than bearing any preconceived ideas or hypothesis about potential findings that is generally found in quantitative research approach. Furthermore, the selection of qualitative approach best suited the purpose and selection of methods required for this current study such as, using Focus Group Discussion (FGD) and interview. As Creswell (2014) stated "the qualitative approach supports a way of looking at research that honors an inductive style, a focus on individual meaning and the importance of rendering the complexity of the situation” (p.4). Similarly, the use of qualitative approach provided me the opportunity to choose methods that facilitated the collection of data in participants' natural setting such as, collecting data through FGD and interviews with the ECEs in the FDK setting. Moreover, the use of open-ended questions during the FGD and interview allowed me to explore and have an in-depth understanding of how ECEs' interpreted their roles 
within the teaching team of FDK program. In order to inform the ongoing data collection, the analysis process happened simultaneously with the data collection in this study (see figure. 1). The use of inductive data analysis (Creswell, 2014) process in this study was helpful to develop initial themes from the raw data, and categorize those into themes that are more general in order to answer the research question. Thus, using the qualitative research approach was instrumental to explore and understand how ECEs' experience, cultural and historical background shape the way they constructed the meaning of their roles within the FDK program.

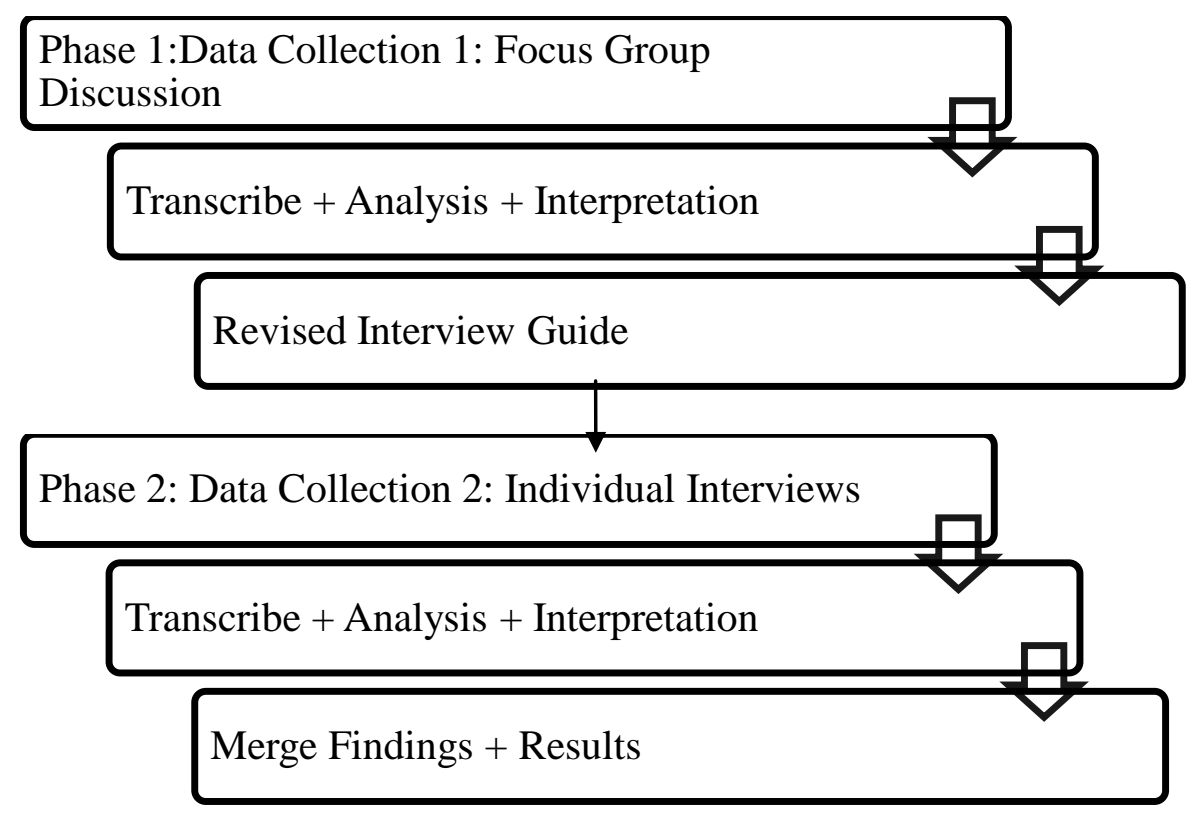

Figure.1

This study aims to construct a better understanding of the ECEs’ perceptions of their roles and responsibilities based on their experiences within the FDK program, and to determine whether the emerging data fits with existing theoretical framework to describe the experiences of ECEs in the FDK adequately. Initially, I planned for face-to-face interviews with 4 ECEs and 2 FGD with 12 ECEs. Due to unavailability of the participants, I could interview 3 participants over the phone and conducted1 FGD with 8 participants. However, out of these 8 participants, 4 
were OCTs who were invited to join a separate FGD as part of the larger study but chose to remain the FGD with the ECEs. I discussed the detail of the FGD and interviews participants and the process in the following sections. In addition, I planned to conduct a document analysis to strengthen the findings of the current study. The process I followed for analyzing the documents is discussed in the section on "data collection tool and process".

\section{Setting, sample, ethics and recruitment}

As I was new to the FDK program in Ontario, during the initial phase of this study, finding access to FDK site and selecting participants was challenging for me. However, with the support of my Professor at the MA in early Childhood Studies Program at Ryerson, I received permission to work as a team member of the 'Schools at the Centre of the Community: A Case Study of Seamless Day Early Learning' research project of Atkinson Centre, OISE, University of Toronto. The purpose was to assist in the research project, and, use a limited portion of data that would be collected by me from the ECEs through Focus Group Discussion (FGD) and interviews for my MRP. The larger study was conducted in the FDK program run by the Waterloo District School Board (WDSB), the Ottawa Carleton District School Board, Hamilton and Halton School Boards and involved educators, parents and school board officials. However, the sample of the current study only focused on the ECEs recruited for the Atkinson Centre research project in the Waterloo District.

The sample selection criterion of the current study included selection of ECEs working in partnership with the teacher within the FDK program, and ECEs recruited for the larger research project perfectly matched the sample selection criterion. The selection of the sample allowed me to involve appropriate participants to answer the research questions guiding this study. The initial plan for this study was to recruit 16 participants due to time constrain to conduct and complete 
the study within a limited time-frame. In order to attain the written informed consent from the participants, an information letter and consent form (attached as appendix D) developed as part of the larger research project was used in the current study. Participants were informed that their participation was voluntary, they could withdraw any time, their personal information would be kept confidential, and no name would be mentioned in the final report.

At this stage, I applied to the Ryerson Research Ethics Board (REB) to approve the current study. As I conducted this study as part of the Atkinson Centre Research project, the original proposal that was approved by the University of Toronto Research Ethics Board was submitted. In addition, I completed the online research application form with all the required information related to my study and submitted to the Ryerson REB. Further amendment took place as the REB needed more clarifications in some areas such as who would be supervising my study, how the research question of the current study differ from the goals of the larger project participants and the process of data collection etc. In discussion with my supervisor, I provided necessary clarifications and resubmitted the application online. The Ryerson REB approved my application at this stage. However, finding research participants was challenging and necessitated reopening my online application form and making further amendment to extend the data collection and analysis period and alter the research design.

The recruitment of the participants remained a challenge from the very beginning of this project. Even though, participants for the FGD were invited through the completion of a survey as part of the larger study, no one showed up during the first FGD arranged in Waterloo. The potential reasons for lack of participation in the FGD might be harsh winter weather, ECEs’ unavailability at the end of the workday and their concern about sharing their experiences in the FDK program. A second FGD was planned at the later time, and 8 participants attended and 
agreed to take part in the discussion. Despite the fact that the participant recruitment plan did not include the teachers working within the teaching team, 4 teachers participated in the FGD along with the ECEs, and added to the total number of the participants. The teachers were invited as a separate group to participate in the larger Atkinson project, but insisted that they did not want to separate from their ECE partners. This suggests that in their collaborative work, two educators started to build a collegial relationship, which motivated them to stay together during the FGD and engage in reflective dialogue. The detail information about participation of teachers in this study has been discussed in the section "data collection tool and process". Following a snowball sampling technique, the FGD participants were requested to inform their ECE colleagues about the current study and were given necessary contacts for further communication in order to take part in the current study for another FGD and face-to-face interview. Follow up process undertook several email communications with one of the ECEs participated in the FGD.

However, due to the adverse weather conditions and the work pressure during that time of the year, no one responded. With the support of the Principal Investigator of the larger project, a second attempt was initiated to recruit participants for phone interview instead of a face-to face interview. This time, one of the Early Childhood Supervisors was contacted (attached as appendix C) and requested to post information (attached as appendix E) about the current study for the FDK staffs at conferences. As a result, 4 ECEs communicated and expressed their interest to take part in the current research. The consent form and information letter were sent immediately as email attachments. Several email communications were made to decide on the time that suits the participants for the phone interview. Three out of four ECEs confirmed their participation and one dropped out. The possible reason for dropping out from the current study might be ECEs' busy schedule at the end of academic year. 


\section{Data collection tools and process}

Qualitative research often uses in depth interviews or semi-structured interviews in order to collect data. With in-depth interviews, researcher engages in conversation with the participant, and asks open-ended questions to gather information based on views and opinions of the participants (Creswell, 2014). Similarly, this study conducted a FGD and over telephone indepth interview in order to have a deeper understanding of the ECEs’ perception of their roles and responsibilities in the FDK. A semi-structured interview guide (attached as appendix A and B) focusing ECEs’ perceptions of their roles and responsibilities in the FDK program was developed to use during the FGD and interview. Separate but related questions were developed in order to guide the discussion and provided scope for additional questions to arise. The questions developed for the FGD and interview were field tested with one of my classmates in order to eliminate any kind of ambiguity.

The purpose of the focus group discussion (FGD) was to explore and understand ECEs' perceptions of their roles and responsibilities based on their experiences, successes, and challenges faced in the FDK program. The FGD was held in the Waterloo region, and involved 8 participants working in the FDK program. The participants were invited to participate in the FGD through the completion of a survey as part of the larger study. Participants’ informed consents were obtained through signing the consent forms at the beginning of the FGD. The FGD took place in a quiet room, within the school in consultation with the WRDSB. The plan was to conduct the FGD separately with the ECEs and the teachers however, the participants expressed their interest to remain in the same group while taking part in the discussion. The discussion session lasted for almost two hours, and was guided by the questions developed for 
the FGD guide. Information discussed by the participants was recorded using a digital tape recorder and secured for analysis.

The 3 phone interviews were held at times set by the participants. Consent form and information letter were sent in advance through email for the participants to read, sign, scan and to send it back before the phone interview. The interview lasted from 45 minutes to an hour and recorded using a digital tape recorder. The guide developed for the interview was followed to guide the discussion throughout the phone interview however, questioning did not follow a particular sequence. One of the participants communicated at a later point for further clarification of the information provided. For both FGD and phone interview field notes were taken in order to record participants impressions, reactions, additional thoughts and for potential codes. Data were transcribed within a short period of the FGD and interviews were held.

In addition to the FGD and phone interview I added a plan to conduct document analysis of key documents related to my study, and reviewed and analyzed key documents including "The Standard of Practice for Teaching Profession" and "The Ethical Standards for Teaching Profession” defined by the Ontario College of Teachers, “Code of Ethics and Standards of Practice” defined by the College of Early Childhood Educators, “Additional Qualification Guideline: Kindergarten Part 1" developed by the Ontario College of Teachers, "Supporting the Ontario Leadership Strategy: Principals Wants to Know” and "Education Act 2014 (Part-X)” and the "Shared Responsibility in the learning Community section" outlined in the document Foundations of Professional Practice. To conduct the data analysis, at first I skimmed through each of the documents to get an overview of the entire document and to look for information that are relevant to my study. Next, I read the document again to interpret the meaning of the content specific to my study findings. The purpose of reviewing these documents was to verify the 
findings thus, strengthen the trustworthiness of my study. In addition, the analysis of the document was helpful to have an in-depth understanding about the educational and training background of the members of the teaching team, and how their positions, and roles and responsibilities are defined in the regulation.

\section{Data analysis process}

I started the process of manual data analysis immediately after the first interview when the ideas were still fresh in my mind. I followed a two-step procedure for analyzing the data, step 1: Initial coding and step 2: developing core category. In step 1, I transcribed the raw data from the interview using MS word. Next, I read all the data several times to get a general idea of the information and reflect on the overall meaning. Next, I read through the data line by line to develop initial coding. When analyzing, I coded the data by labeling the emergent ideas and issues with different colored highlighters. For example, I highlighted sections that discussed undefined roles, planning time, pay, training need etc. I looked at the initial codes at this stage, and made necessary modification in the interview guide. This included small changes like reorganizing the questions or adding sub-question to the existing interview guide. The necessary modification of the interview guide was helpful to fill the gaps in the existing data set with information required to inform the categories under development. In step 2, I selected the codes that are most important for the analysis to generate a set of core category. This process included development of a chart listing all the initial codes developed for the entire data set and finally collapsed to form core category (See figure.2).

In addition, I considered the meaning of the initial codes that was developed at the initial stage to find similarities and differences, and to explain the data. I repeatedly examined the data to obtain all available insights to check against the codes. The findings were compared with 
existing information and theoretical framework to determine the extent to which they confirm or diverge from the existing literature. Due to the time constraint of the participants of the FGD and phone interview, I conducted the peer debrief through arranging meetings with one of my classmates in order to check the accuracy of the findings to get feedback on the accuracy of the data. This means, I have shared the major themes that emerged from the data instead of the raw transcripts.

\section{Limitation}

The study was limited in several ways. First, due to time constraints, limited financial resources and participants' availability, I was not able to collect as much interview data as I intended. In particular, I planned to collect data through conducting Focus Group Discussion only with the early childhood educators (ECEs) however, as both ECEs and OCTs wanted to remain in the same group, therefore, it was not possible to have a separate FGD with the ECEs. Moreover, due lack of participants during the harsh winter weather, I could not conduct a second FGD with the ECEs. Due to time restrictions, I could not plan for an extension on the study and recognize this creates limitations on my data analysis. From this perspective my study may seem to have less potential to generalize the findings to all ECEs working in the full day kindergarten program however, my study aimed to focus on the findings from the context of a particular site. Good qualitative research focuses on the specific description and emergence of themes from the context of a particular site (Greene \& Caracelli, 1997 as cited in Creswell, 2014). However, the addition of document analysis, strengthen my research study and provided an opportunity to consider the policy implications of my findings.

Secondly, due to the end of school year participants were unavailable for face-to-face interview. As a result, I had to interview the participants over the phone. Unavailability of the 
participants due to their professional workload followed by the summer vacation also hampered the follow up member check with the participants. In order to ensure the trustworthiness of the study, I used peer debriefing to ensure the accuracy of the findings. In addition, I conducted a brief review of some key documents to strengthen the accuracy of the findings that emerged from the data of this study.

Thirdly, as the interviews were recorded on the phone, I had to transcribe the data with extra care. I checked the data several times against the recording to avoid as well as identify any mistakes that took place during transcription.

Lastly, not all participants of this study provided detailed information during the interview and FGD about their perceptions of their roles and responsibilities in the FDK program. This may be because of my inexperience in designing such questions and interviewing participants whose interpretation of the terms are different from mine, or they were not comfortable enough to share all of their experiences in the FDK program with me as a student researcher. 


\section{Results and Discussion}

The purpose of this study is to understand ECEs' perceptions of their roles and responsibilities in the full day kindergarten (FDK) program. Focus group discussions (FGD) and in-depth interviews were conducted based on the assumption that ECEs' lived experience in the full day kindergarten (FDK) would be a starting point to understand how ECEs shaped their perceptions of their roles and responsibilities. The three themes that emerged based on ECEs' lived experience regarding their roles and responsibilities in the FDK program were instrumental in answering the research questions. These themes namely "ECEs' differentiated roles", "Power Dynamic between ECEs and OCTs" and "ECEs' agency” were helpful to gain a deeper understanding about how ECEs' lived experiences shaped their perceptions of their roles in the FDK. In addition, I analyzed five key documents to justify the findings of my study.

\section{Document review}

I reviewed and analyzed the documents to gain deeper understanding about FDK legislation, the professional background of the educators and how their positions, roles and responsibilities, and support strategies are outlined in these documents. These five documents included, "Education Act, 2014 (Part-X)”, “Code of Ethics and Standards of Practice” of early childhood educators in Ontario, "The Standard of Practice for Teaching Profession” and "The Ethical Standards for Teaching Profession”, “Additional Qualification Guideline: Kindergarten Part 1" and "Supporting the Ontario Leadership Strategy: Principals Wants to Know”. In addition, I reviewed the "Shared Responsibility in the learning Community section" outlined in the document Foundations of Professional Practice to further strengthen the findings of this study. In the next section, at first I present the brief analysis of the document, and the key findings followed by a brief discussion in the context of the current study. I used these key 
findings to verify the themes that emerged from the analysis of Focus Group Discussion and interview data, and discussed under the "Analysis of theme with theory, literature and document review" section located within each theme.

\section{Education Act, 2014}

The education act is the overarching legislation that governs the education system in Ontario through the Ministry of Education (Ontario Ministry of Education, n.d.) and is divided into several subsections. In the context of current study, the review of the Education Act, 2014(Government of Ontario, 2014) focused specifically on the duties of the teachers, ECEs and the principals. The review of the Education Act, 2014 illustrated that both teachers and ECEs have a "duty to cooperate" (Part-X, section 264.1) in planning and delivering the FDK curriculum. "Nothing in this section limits duties of the teacher" (Part-X, section 264.3) in relation to report cards, assessment of the students, classroom management, and preparation of teaching plan (Government of Ontario, 2014).

Use of such language highlighted the leading role of the teachers in some areas in relation to their duties in the FDK classroom. Whereas, nothing in the act emphasized on ECEs' duties in relation to report card, assessment, classroom management or preparation of the teaching plan, and left ECEs' roles open to different interpretation in relation to these areas. Defining one educator's role clearly over the other may lead to misinterpretation of the roles of both educators, and has the potential to position them as a binary.

In line with educators' role definitions in the Education Act, 2014 (Government of Ontario, 2014), it is important to see how the members of the teaching team interpreted their rolesin the context of the current study. Although, reviewing Part-X, section 2.3 illustrated a 
distinction between the roles of the two educators, the duties of the principals outlined in the act (Government of Ontario, 2014) highlighted that their role was to "develop co-operation and coordination among the staffs in the school” (Government of Ontario, 2014, Part-X, section 265.1). This suggests that despite distinctions in the roles of the educators, collaboration and cooperation is necessary. This also suggests that the roles of principals as leaders of the schools were recognized in the policy as facilitators of collaboration between the educators to perform their shared responsibilities in the FDK program.

Findings from the above analysis of Education Act, 2014 revealed that although much emphasis is given on educators' shared responsibility in planning and delivering the FDK curriculum, defining teachers' roles in certain areas such as instruction, assessment and classroom management more clearly compare to ECEs’ roles which resulted in ECEs’ roles being unclear in the respective areas. While collaboration and coordination were identified as key strategies to deliver the FDK curriculum, principals' roles were emphasized to facilitate such collaboration between the educators for successful implementation of the program.

The above findings suggest that ECEs' unclear roles in certain areas resulted in lack of understanding about ECEs roles and responsibilities-which led to lack of direction on the principals' part in clearly defining the ECE role in the FDK program, thus caused power imbalance within the teaching team. Gibson and Pelletier (2011) also found such hierarchical structure and highlighted its detrimental effects on the quality of team teaching.

Foucault’s lens of "power/knowledge" supports understanding of how in their power relationship, both educators can engage in reflective practice within the FDK program with the support from the principals. To engage in reflective practice, it is important to understand the process in which the power circulated within educators' relationship. As power has the capacity 
to define how individuals should perform their roles, therefore, using power in its productive form allow ECEs to further the knowledge about their roles through engaging in reflective dialogue with their teaching partners. Additionally, supports from the principals encourage educators to involve in reflective practice often in order to strengthen their collaborative work. Review of the document developed by Ontario Ministry of Education (2012) in the next section described strategies that were developed to support and guide the principals to facilitate collaboration between the educators.

\section{Supporting the Ontario leadership strategy: Principals wants to know: Supporting}

\section{educator teams in the fill day kindergarten}

This document is one of the series tip sheet developed by the Ontario Ministry of Education to support principals’ instructional leadership practice (Ontario Ministry of Education, 2014).The tip sheet (Ontario Ministry of Education, 2012)considered for this study focused on strategies for supporting and reinforcing collaboration between the members of the teaching team.

Suggestions highlight greater emphasis on the collaboration between ECEs and OCTs, and their diverse but complementary skills to create a responsive learning environment to support children’s individual needs (Ontario Ministry of Education, 2012). In addition, understanding the relationship of the educators through acknowledging their distinct roles within the teaching team is suggested as one of the key strategies for the principals when supporting the educator team (Ontario Ministry of Education, 2012). According to Ontario Ministry of Education (2012), “while recognizing that a positive and respectful working relationship cannot be codified or universally defined, the roles of the teacher and ECE in an FDK program have certain distinction” (p.1). This highlights that principals play an important role in acknowledging 
and promoting the distinct but complementary roles of the educators through facilitating collaboration between them.

However, suggestions for principals also emphasize that according to the legislation governing FDK program, the members of the educator team are obliged to cooperate in planning and implementing the FDK program and the focus of their relationship should be the similarities in their roles rather than focusing on their differences. Sharing experiences, developing a trusting and respectful relationship and open communication are suggested as strategies to establish successful partnerships within the teaching team. Inclusion and invitation are identified as crucial strategies to create a space for both educators to negotiate their new identities in the FDK program.

Creating such space for the educators enables principals to learn more about the work of the educator team within the play-based early learning program, thus, recognize and acknowledge each educator's knowledge and professional background. Moreover, the use of language such as “avoiding deference to any member over the other” (Ontario Ministry of Education, 2012, p.2) highlights and promotes principals’ unbiased role in building a collegial relation between the educators. Taking such neutral position supports principals to build a strong relationship with the educator teams, establish effective communication and identify potential causes of conflict. It is important to note that the use of words like "share, collaboration, open communication, respect and trust” (Ontario Ministry of Education, 2012) were evident throughout the document and indicates the supportive roles of the principals to create a work environment where both educators' roles are understood and valued.

Findings from the above analysis emphasized the need for greater understanding of ECEs' distinct but complementary roles within the teaching team, and the dynamics of their 
relationship with their teaching partner. Findings also highlighted principals’ leadership role to facilitate the development of a respectful and trusting relationship between the educators through providing a platform to negotiate their identities and sharing their experiences and concerns. Such a platform allows educators to accept and understand each other's different but complementary role. Moreover, accepting the differences in educators' roles is another important finding that stemmed from the analysis of this document. Understanding educators' roles and their relationship through the lens of "third space" has the potential for new perspectives to emerge.

In the context of the current study, both the literature review and key findings, which I discuss in the next section, suggest a lack of understanding about the ECE role led to lack of direction on principals' part in defining ECEs' roles in the FDK program (Ministry of Education, 2013). Comparing the findings against participants' experiences of support from their principals was helpful to learn how having a greater understanding of the ECE role and dynamics of educators' relationship among principals is linked with the kind of support they offer to the educators. Reviewing the Code of Ethics and Standards of Practice of both early childhood and teaching professions in the next section would help to understand how the guiding philosophy of both professions facilitate successful implementation of the teaching team in the FDK program.

Code of Ethics and Standards of Practice of Early Childhood Educators in Ontario and the Ethical Standards for Teaching Profession and Standard of Practice for Teaching Profession

The Code of Ethics and Standards of Practice was developed by the College of early Childhood Educators and approved in 2011(College of Early Childhood Educators, 2011). The purpose of the Standards of Practice is to outline standards for ECEs' professional practice and 
conduct whereas, the Code of Ethics outlines Ethical Standards applied to the professional practice and conduct. The Ethical Standards of Teaching Profession presents a vision for teachers’ professional practice and their commitments towards their students and their learning (Ontario College of Teachers, 2000).

The Ethical Standards of both professions integrates care, respect, trust and integrity as a core set of beliefs and values (College of Early Childhood Educators, 2011; Ontario College of Teachers, 2000). Such as the review of the document Ethical and Professional Standards for Early Childhood Educators (College of Early Childhood Educators, n.d.) suggests, "ECEs have responsibilities to children, families, their colleagues, the profession and to their community and society. Their practice reflects a core set of values of care, respect, trust and integrity” (Care, Respect, Trust and Integrity section, para.1). Similarly, the review of the Ethical Standards for the Teaching Profession and Standards of practice for the Teaching Profession (Ontario College of Teachers, 2000) suggests care, respect, trust and integrity are at the core of the teaching profession. This suggests that members of both professions have a commonality in their professional beliefs and values that guide their professional practice and conduct.

In addition, both members of College of Early Childhood Educators and Ontario College of Teachers are expected to maintain a relationship with their colleagues that demonstrate respect, trust and integrity (College of Early Childhood Educators, 2011, Ontario College of Teachers, 2000). The Code of Ethics of ECE profession highlighted "early childhood educators interact with their colleagues and other professional in ways that demonstrate respect, trust and integrity” (College of early Childhood Educators, 2011, p.11). This correlates with the Code of Ethics for the teaching profession that expects members demonstrates a trusting relationship with their students, families, colleagues and other professionals. The Standards of 
Practice of both professions highlights the need for building effective relationship through open communication and reflective practices. However, the Ethical Standards and the Standards of Practice for the Teaching profession emphasized the leadership role of the teacher in recognizing their shared responsibilities as well as facilitating students' learning success. This suggests that the members of the teaching team build a respectful and trusting relationship through reflective practice in order to successfully-deliver the FDK program. However, reflective practice does not happen automatically; rather it involves educators' initiative to take control of their own learning and challenging their own work and pedagogical practice in order to define their own identities (Mac Naughton, 2005). Having such guiding philosophy that promotes collaboration between educators based on respect, trust and integrity can be instrumental to understand the roles of the members of the teaching team from different perspectives.

Review of both documents also depicted that members of both professions are expected to recognize the need for ongoing professional development and remain updated in their professional knowledge. Such as the Code of Ethic of ECEs outlines, "early childhood educators value lifelong learning and commit themselves to engage in continuous professional learning to enhance their practice” (College of Early Childhood Educators, 2011). This means ECEs remain updated in their knowledge and practice of child development and early learning to provide continuous support for the learning success of all children. Similarly, the Standards of Practice of teaching profession highlights "members strive to be current in their professional knowledge and recognize its relationship to practice” (Ontario College of Teachers, 2000, p.1) thus, expects teachers to remain updated in the knowledge and practice of student development and pedagogy of teaching. This correlates with the findings of the current study where participants highlighted the need for further professional development in order to gain deeper understanding of each 
other's roles thus, enhancing their teaching partnership. However, it is important to consider that educators' recognition of their need for professional development requires support and action on the principals' part.

Findings from the above analysis suggest that care, respect, trust and integrity are the core set of beliefs and values of both ECE and teacher's professions that guide their day to day practice and their interactions with children, families and other professionals. Findings also suggest educators' should build a respectful and trusting relationship based on the core set of beliefs and values of both the ECE and teaching professions. Having such a respectful and trusting relationship is crucial for reflective practice and self directed learning among the educators while performing their shared responsibility. Educators' agency in advancing their knowledge and professional practice through identifying their professional needs was also highlighted in the findings.

The findings that emerged from the analysis of Ethical and Professional Standards of both professions correlate with the findings from the review of the literature as well as findings underpinning the themes. Despite their experiences of challenges, in most cases the members of the teaching team reflected the guiding philosophy of their respective profession in their practice and interaction with others. However, findings from literature and the current study suggest that a better understanding of these core set of beliefs and values is needed to understand each other roles, knowledge and professional background in order to develop a collegial relationship. In the next section, I presented a brief analysis of the "Additional Qualification Courses Guideline Kindergarten, Part 1". As mentioned by one of the teacher participant of the current study that this course supported her to understand the ECE role and their professional background, I reviewed the course outline to enhance my knowledge the credibility of the current study. 


\section{Additional qualification courses guideline kindergarten, part 1}

The Additional Qualification Courses (AQ) course part 1 is identified in the Teachers' Qualifications Regulation to improve teachers' education practices, and developed based on the Ethical Standards and the Standards of Practice for teaching profession (Ontario, College of Teachers, 2013). The analysis of the documents illustrated several important findings that are crucial in the context of the current study.

Firstly, the review of the document depicted that the teachers are expected to have an understanding of the Ethical Standards and Standards of Practice for the teaching profession specifically, "understanding and embodying care, trust, respect and integrity” (Ontario College of Teachers, 2013, p. 5). Having such understanding can be instrumental for the OCTs to understand that in the context of FDK program, ensuring effective learning experiences for students depends on effective collaboration between the educators through building a collegial relationship. Role modeling a relationship that is based on respect, trust and integrity is crucial to create a learning environment where students feel included, safe and supported in order to excel in their learning success.

Secondly, the theoretical foundations of Kindergarten Part 1 course include theories of child development and the conceptual and theoretical framework of early learning. More specifically, the course content has a greater focus on the role of play-based learning in children's development, and how literacy and numeracy learning is embedded within all aspects of children's development. In addition, the course content emphasizes on teachers' engagement in professional conversations with their colleagues in order to critically analyze the relationship between theory and practice in early learning (Ontario College of Teachers, 2013). In the context of the current study, the course contents seem to enables OCTs to develop an understanding 
about ECEs professional knowledge and competencies that leads to understanding of the ECE role in the FDK program. This also allows them to exchange their professional knowledge and experiences with ECEs when planning and implementing the play-based learning for the children in the FDK program.

Lastly, the course content highlights "understanding and respecting the importance of shared responsibility and partnership” (Ontario College of Teachers, 2012, p. 9) as mentioned in the Foundations of Professional Practice document which encompasses collaborative partnerships, reflective dialogue, inquiry and self-directed learning are among the foundation of learning communities” (p. 19) in order to support students' success. It was interesting to review the Additional Qualification Guideline Kindergarten, Part-1 because of its effectiveness in the context of the current study. The course content covered key elements like care, trust, respect and integrity that uphold the Ethical Standards of both ECE and teaching professions, knowledge of child development and early learning, and understanding shared responsibility. Together all these elements acted as an apparatus to understand educators' perceptions of their roles in the teaching team.

Findings from the above analysis suggest consideration of Additional Qualification Guideline Kindergarten, Part-1 for the teachers to learn about play-based curriculum and knowledge and professional practice of the ECEs. Findings also suggest considering the course supports teachers to build a respectful and trusting relationship with their partner based on the core set of beliefs and values of teaching profession. Having such relationship with their teaching partner would allow them to initiate reflective practice in order to excel in their collaborative work in the FDK program. 
The above findings have the potentials to support teachers to understand ECEs' distinct but complementary roles within the teaching team and their professional knowledge and practice. Lack of understanding about ECEs' roles and responsibilities among the teachers was a recurring issue embedded in both review of the literature (Ministry of Education, 2013) and also in the themes emerged from the data. Although, factors like differences in professional status, working condition, salary etc. (Gibson \& Pelletier, 2011) contributed towards power imbalance within the teaching team, having an understanding of ECEs' professional knowledge and practice has the potential to build a collegial relationship within the teaching team.

\section{Summary of the document analysis}

In sum, the findings from the analysis of the key documents suggest that teachers' roles in the policy are defined more clearly than of ECEs. Findings also emphasized the need for clear understanding of ECEs' distinct but complementary roles within the teaching team, and the dynamics of their relationship with their teaching partners. Principals' leadership role is highlighted to facilitate a collaborative relationship between the educators and accepting each other's differences. Such relationship should underpin care, respect, trust and integrity, the core set of beliefs and values of both ECE and teaching profession. The findings also depicted that establishing a respectful and trusting relationship is crucial for reflective practice and self directed learning among the educators while performing their shared responsibilities. Together all these findings from the document review informed the themes in order to better understand ECEs perceptions about their roles and responsibilities in the FDK program.

\section{Key thematic findings}

The key themes that emerged from Focus Group Discussion and interview data correlated with the post-colonial and post-structural theoretical framework and methodology, and suggested 
that ECEs perceptions of their roles and responsibilities can be better understood through giving them voice and listening to their lived experiences. The three major themes (core categories) were developed based on the initial codes that emerged from the analysis of the data. The following chart illustrates examples of "Initial coding and Core category/Major themes" .

\begin{tabular}{|l|l|}
\hline \multicolumn{1}{|c|}{ Initial Coding } & Core Category/Major Themes \\
\hline $\begin{array}{l}\text { Traditional notion of ECE role, role confusion, separated, } \\
\text { misinterpretation of ECE role, unequal workload, confusion, } \\
\text { undefined role, role division, administrator's limitation of } \\
\text { defining roles, administrator/board expectations, lack of } \\
\text { understanding on administrators' part, low pay, pay versus } \\
\text { workload, lack of planning time }\end{array}$ & ECEs' differentiated role \\
\hline $\begin{array}{l}\text { Conflict, lost communication, no say, hierarchy, conflict due } \\
\text { to educational background, division }\end{array}$ & $\begin{array}{l}\text { Power dynamics between ECE and } \\
\text { OCT }\end{array}$ \\
\hline $\begin{array}{l}\text { Unionized, raising voice, need for more training, role } \\
\text { definition during training, lack of expertise, opportunity for } \\
\text { professional development, ECEs interest area. }\end{array}$ & ECEs' agency \\
\hline
\end{tabular}

Figure 2

The first two themes namely ECEs' differentiated role, and power dynamics between ECE and OCT, illustrated ECEs' lived experiences in the FDK program, and highlighted how ECEs' perceptions of their roles was shaped by everyday successes and challenges they encountered within the teaching team, with the children, and other members in the school community. Interestingly, the issues that surfaced through these themes, and constituted ECEs' perceptions of their roles, are already present in the ongoing discourse on the teaching team and their roles and responsibilities. The third theme shed light on how ECEs working in the FDK classroom found their voices through identifying their complementary roles, their needs and making recommendations to improve their partnerships in the FDK program. In other words, ECEs in this study demonstrated their agency to highlight the distinct expertise they brought to 
the FDK program. In the following section, I present each theme at a time and verify it with literature and findings from the document analysis.

\section{ECEs’ differentiated role}

The analysis of the FGD and interview data revealed that ECEs working in the FDK program had clear understanding of their roles and responsibilities from their own perspective, however, had different experience in relation to their lived reality within the FDK program. Participants interviewed described that their roles in the FDK was to support children's learning and development. One participant described, "I find my role is to teach and educate students in my class and to make sure that developmentally they are growing” (Interview participant 2).Interestingly, ECEs highlighted their complementary roles within the teaching team. When asked to what extent their roles was different or similar compare to OCTs' roles, one of the participants mentioned,

"I heard that the OCT are more about curriculum, and ECE are more about behavioral. In my particular situation, I sit down with my OCT and we just go over everything... we do a lot of similar work but she takes more of a curriculum role.” (Interview participant 1)

Another participant stated,

"It's different context. I do a lot of the care-giving and that kind of work, maintaining the environment and keeping it cool...a lot of that personal care with children. She looks at their guided reading program...she kind of looks after that part and everything else is similar.” (Participant 2)

This suggests that ECEs working in the FDK classroom are aware of their roles as well as their partners' complementary roles. This also highlights educators' initiatives to sort out their roles within the teaching team. One of the FGD ECE participants described her role as supplementing or adding to the OCT's role of teaching literacy and numeracy with science, arts and outdoor activities. 
However, ECE participants of also shared different experiences in relation to their working experience with their teaching partners and other members in the FDK program. Several issues such as, lack of understanding about their knowledge and expertise among the administrators, lack of planning time to network with other teaching partners, unequal workload and pay differentiation between ECE-OCT seemed to act as barriers in clearly defining the roles and responsibilities of the ECEs in the FDK program. The following sections illustrated the findings around these issues within the current theme.

Most of the ECEs participated in this study faced some challenges while performing their roles in the FDK program. They found that their ECE role was not articulated clearly among the staff members and was open to different interpretation. One participant described her experience during the first year in FDK and mentioned,

"My first year was really challenging. I was definitely seen as a helper...it was a big switch...my teacher had this vision... it was her idea like any kindergarten teacher, I would take care of water, painting, stuffs like that and she would do literacy and math, and I kind of seeing that literacy and math kind of happening through everything...I feel lot more confident now”(Interview participant 2).

Considering the lens of "Other” illustrates how the OCT interpreted the ECE's roles based on her assumptions and made the ECE feel "othered". Here, the lens of "power/knowledge" supports to understand how the way the ECE role has been portrayed in the dominant discourse influences the teacher to exercise her power over the ECE. However, as power circulates in all relationships at different time points, so the ECE starts to critically reflect on her situation and explains that literacy and numeracy are integral part of children's development. Thus, as the OCT devalues ECE's role,the ECE leverages her own power.

Another participant mentioned "there is no clear definition...there are different interpretations of what the Ministry is saying, what the curriculum is saying, principals have their 
own interpretation, administrators have their own interpretation, so it's a little bit difficult to navigate.” (Interview participant 3)ECE claims of their role confusion was also validated by one of the OCT participated in FGD. The OCT expressed her frustration regarding what was happening around the implementation of FDK program and misinterpretations of ECE roles and stated,

"Right now it's so disconnected and sometimes, you go and you just want to smash your face into the table because it's so heart-wrenching and maddening and frustrating to hear what's happening... and it frustrates me because I think that also leads to a misunderstanding of ECE role. They don't understand what ECE brings to the relationship. They see themselves as the teacher and the only other person who comes into rooms are-oh, you are my assistant, right.” (FGD teacher participant / OCT)

Here, the OCT highlights how ECEs are viewed as strange or unfamiliar identities in the FDK program. Looking through Edward Said's lens of “Other” reveals how some OCTs are unaware of their shared responsibility and “othered” ECEs through defining their own identities as teachers. Moreover, Foucault’s lens of “power/knowledge” helps to understand the power relationship between the OCT and the ECE. The teacher participant highlighted how considering the additional qualification courses like, Kindergarten part-1 helped her to understand the ECE role and mentioned "I feel that because I went to the AQ course, I understood the partnership thing, and ECEs I have worked with have enjoyed working with me.”

ECEs in the FGD also mentioned that not having a clearly defined role of the members of the teaching team created confusion among the team members, one of the FGD ECE participants stated, “

I just think the roles of the ECEs and the teachers hasn't been clearly defined and has also been evolved over the time but not necessarily at all locations......as we sort of got deeper into it, you know it just seemed as though there was no defined who does what." 
ECEs participated in the study also highlighted that although they managed to sort out their own within the teaching team, lack of understanding on the administrators' part sometimes made it difficult to perform within the classroom. One ECE FGD participant mentioned, “....when they would come in and see what we were doing, she would say no, no, no, she shouldn't be doing that and I would think that wow, why are you spanking me for this because you didn't tell me what she would be doing and we have worked this out in our own sort of relationship in the classroom and with the children...nothing has been said as far as the teacher will do this pocket of information and then the ECE will do this pocket. Nothing has been defined.”

Here a post-colonial lens of "Other” and "hybridity” suggests how ECEs' roles are viewed and understood differently within the FDK classroom however, indicates ECE's activist position to sort out her role with her teaching partner. Both ECE and teacher participated in the FGD discussed how administrator's expectations differed every year, also from school to school. The FGD ECE participant stated, "they are really pushing this year much more so than last year, to make sure ECEs are part of the report card”. The FGD teacher participant added to this and mentioned, “I think that's an administrative thing, because, this year I found where I am working, I think he (the principal) wanted me to involve them (ECEs) versus last year. It depends on who you work for."The lens of "power/knowledge" here suggests the principals exercise their power at different time points to change the way ECEs should perform their roles within the FDK classroom. The review of the document Supporting the Ontario leadership strategy: Principals wants to know: Supporting educator teams in the fill day kindergarten (Ontario Ministry of Education, 2012) emphasizes that regardless of varying working condition from school to school, principals need to support the educator team based on the criteria of inclusion and invitation. However, the given situation illustrates that due to lack of understanding about ECEs’ role, ECEs roles are changing every year depending on the situations. 
The ECE FGD participant argued,

I think they've coordinated our PD to be completely separate. On days when I could have been working with my partner she had to be at a workshop. I don't think it's administration saying thou shalt work or not work. I think it's been coordinate for you not to be able to. They have actively made sure we are not in the school on those days.

However, both interview and FGD ECE participants mentioned they collaborated with their

OCTs during the report card time. In addition, ECEs also mentioned that a greater understanding

is needed about ECEs’ roles and responsibilities among the principals for the teaching team to

leverage its expertise to the fullest and highlighted,

"Yes, there are some principals who refer to ECEs as EAs which means, we can do our job without EAs, but it's very, very different position...I think it's because of lack of education, lack of familiarity... and they need to be helped as well. They came from being a teacher to principal and vice-principal, so they know that bridge. But, being an ECE, it’s unknown.” (Interview participant 3)

Here the lens of "Other" supports the understanding of how the image of ECEs as unfamiliar and unknown identities in the public school sphere led to external construction of their roles.

Interview data also highlighted that support from administrators act as encouragement for the teaching team to perform smoothly within the FDK classroom. One interview participant described,

"Sometimes the principal, honestly, she would just come down and check the room and be like how is their day going or, is there anything they need. These things are amazing, and may be we are smaller school. It's great that the top of the chain would come down and check how things are going.” (Interview participant 1)

This illustrates principal's initiative to uses strategies depicted in the review of the document (Ontario Ministry of Education, 2012) and offers a more balanced approach to supervision of the educator teams. The ECE participant appreciated the open door policy of her school where any of the staff members can go and discuss with the principal if there is an issue. She stated the “mediator meeting” as a useful strategy for the teaching team to discuss problem and issues with 
the principal privately in order to find solutions. However, she also informed that she never went through that process and tried to solve problems on her own, because she knew that her principal would expect them to find positive ways to diffuse those problems.

Both FGD and interview data surfaced lack of planning time as an issue that hindered greater communication, collaboration and networking between the members of the teaching team. Most of the interview participants mentioned OCTs having lot of planning time compare to ECEs having none. One interview participant complained that lack of planning time forced her to use her personal time to meet the OCT. She also mentioned that lack of time to meet the OCT created misunderstanding among the team members and stated,

I find it sometimes our communication is lost or misunderstood. Just because, three people, it's almost like three bosses. Three important figures in the room and we do our best. Think of the same message for the children, and even in instances if one of us is not there, children do their own kind of thing and we do a bit communication. Also, having the time to network, I find a lot of that keep coming back to that..if there were more concrete time, I think, it would be little smoother in the room. (Interview participant 1)

A post-colonial perspective here supported the notion of "fixity" (Bhabha, 1994, p. 66), and suggested interaction between two educators to negotiate their new identities.

Another interview participant said that she really missed the planning time she used to have in the childcare centre and stated that it was opportunity to meet as a team and look at children's portfolios. She identified that these meeting are beneficial for planning and stated,

We went through the portfolios, we undated them, we really talked about where they are at, where they are going, and then from that when we started doing a lot of planning...weall knew where we are at...so that's what I think really beneficial” (Interview participant 2).

This suggests how ECE's previous background and experiences contribute as she shaped her new identity in the FDK program. Participants of the current study also highlighted ECEs' pay and working conditions as significant factors hindering the performance of the teaching team. 
Like planning time, differentiated pay and unequal workload were two other issues highlighted by both ECEs and the OCTs participated in the study. Participants from the FGD mentioned that they recognized that the members of the teaching team shared same amount of work-load but paid differently. One of the FGD teacher participant pointed that their workload increased during the report card time and stated,

Come report card time, all observations and assessments are taken in from everyone but the amount of time that even gets spent on the report cards, my partner has a family, I'm not going to ask her to stay until 5 or 6 or 7o'clock at night... what she gets paid does not qualify me to impinge on her time...I think they are asking you to do a boatload of work for not a lot of pay, and it just doesn't seem to be fair.” (FGD teacher participant)

Another participant who joined the program knowing about the differentiated pay scale and mentioned, "I feel like we are unequally paid, and I walked in on that knowing full hundred percent and I'm okay for now, but if it continues on that, I'm not sure I would stay in the program” (FGD ECE participant).

In her statement, the participant highlighted the difference and inequality in educators' pay that contribute towards power imbalance or the supremacy of the OCTs' over the ECEs. However, it was obvious that in the process of negotiating her identities the participant was raising her voice against the oppression of low pay.

The participants revealed that ECEs did not get paid during the school break such as summer break, over the Christmas, fall break and over the March break. Participants interviewed stated OCTs' higher pay seemed to be legitimate because, the duration OCTs spent to earn their required qualification was longer than the duration ECEs had to spend for their diploma. However, the participant argued that ECEs' working experience should be considered as equivalent to OCTs academic experience in school. She explained that as OCTs learn in their school, ECEs also learn new things every day in their work. 
In general, the study participants mentioned that their pay is low compare to the OCTs' pay and the amount of workload, and highlighted that the overall ECE pay should be increased for the type of work they do and regardless of wherever they work.

\section{Analysis of theme with theory, literature and document review}

The key messages from the first thematic finding suggest that despite their experiences of challenges ECEs recognized and acknowledged their complementary roles within the teaching team. The key messages also highlighted the need for principals to better understand educators' relationships. Although ECEs knew their complementary roles within the teaching team, misinterpretation of their roles among some of the OCTs and administrators, differentiated pay and working conditions made them feel differentiated in the FDK program. For example, participants stated that due to the unclear role definition, in some cases the ECE role was interpreted as "helper" or "assistant" in the classroom. The lack of understanding about ECEs' knowledge and background among the principals made it even harder to articulate the ECE role within the teaching team. As a whole, this positioned ECEs as "Other" in the FDK program.

Similar findings were depicted by Vanderlee, Youmans, Peters \& Eastabrook (2012) who cautioned that lack of understanding and attention in defining the ECE role may lead the staff members of the school to interpret the role differently. This was evident within the first theme where participants reported that they were viewed as helper, Educational Assistant (EA) or assistant in the FDK classroom. Vanderlee et al. (2012) also argue that unlike OCTs, ECEs do not have a generally accepted and shared image within the school, which indicates lack of initiative on principals' part to recognize and promote the professions of ECEs' within the broader school community. 
The lack of direction from the principals to support the members of the educator team to collaborate (Tozer, 2012) seemed to stem from lack of understanding about ECEs' knowledge, skills and professional background (Gananathan, 2011), which was also reiterated by participants of the current study. Review of the literature depicted that differences in professional status in relation to pay, working condition i.e. lack of joint planning and professional development time, differentiated workload, status and educational background hindered the performance of the educators team(Gibson \& Pelletier, 2011). Both ECE and OCT that participated in this study highlighted similar factors when describing ECEs' experiences within the FDK program.

A post-colonial lens of "Other" supports the notion that ECEs in the FDK program were "othered" based on the ways they were perceived "different" compare to OCTs, and placed ECEs and OCTs in two different binary positions of colonized and colonizer

(Osterhammel, 2005). Considering Edward Said's theory of Orientalism (1979), ECEs were new in the academic environment of kindergarten classroom that was once recognized as the realm of OCTs for many years. To OCTs and other members of the School community, ECEs were thus represented as “Orient”, and their role in that territory was interpreted based on assumptions without knowing much about their knowledge and professional background. Like people of dominant west, principals and OCTs often lacked in expert knowledge about the ECE expertise, and considered ECEs an unfamiliar entity within the academic environment of school. Thus, the members of the school could not visualize the complementary role ECE had to offer within the teaching team, and positioned them as "Other".

In contrast, Home Bhabha’s lens of "hybridity" and "third space” and Foucault’s lens of "power/ knowledge" were instrumental to look beyond the binary positions of the members of 
the educator team to trouble aspects of the ECE role. For example, although some of the ECE participants experienced their role confusion within the FDK program and felt differentiated, others highlighted the complementary skills they brought to the teaching team, and how their roles added to OCTs' roles in planning and delivering the curriculum. This suggested that while sharing their responsibility in the FDK classroom, ECEs and OCTs constantly interact in their roles in the process of hybridization. In constant negotiation of their roles, ECEs are supported by their knowledge and professional practice to identify the complementary skills they offer within the teaching team. Although, the findings under the current theme depicted OCTs' exercise of power over the ECEs, the power circulates as ECEs start to reflect on the way they are treated and their identities are constructed within the FDK program.

In addition, findings also showed how support from administrators, such as visiting the classroom and discuss the work of the educator team, open door policy of the school to discuss issues, and resolve conflicts influenced the performance of the integrated team positively. This interaction among the ECE, OCT and principal demonstrated the process of hybridization, and indicated policy direction to consider systematic change that promotes interaction among the staff members and creates platform for them to produce new knowledge regarding the new roles of the educator team. Moss and Balduzzi (2013) also suggests opportunity for creating a platform for building connections and sharing experiences in order to enhance educators' pedagogical practices. Interestingly, the training the principals receive reinforces these ideas (Ontario Ministry of Education, 2012).

Suggestions for principals emphasize collaboration between the members of the teaching team through focusing on their complementary role rather than their differences, building a trusting and respectful relationship between the two educators and recognizing, acknowledging, 
and promoting ECEs' professional knowledge and practice within the greater school community. This coincided with findings underpinned the current theme where participants highlighted the need for greater understanding about ECEs' role among the administrators, and effective communication among the educators in order to strengthen their teaching partnerships.

Moreover, considering the policy direction on the leadership roles of principals to support educator teams as the "third space" supports school administrators to produce new knowledge about the members of the educator team specifically, about the knowledge and expertise of the ECEs. On the other hand, the policy direction supports the educators to negotiate their new identities in that "third space". However, this production of new knowledge is not limited to the principal rather open to the OCTs as well. One of the findings that illustrated how an OCT could develop different understanding about the ECE was through “Additional qualification courses kindergarten, part 1" as a professional development activity. This highlighted how in the process of hybridization the OCT stepped up to encompass her new identity as a teaching partner and considered the course to develop new knowledge about FDK and ECE profession. The review of the document Additional qualification courses guideline kindergarten, part 1revealed that the contents have a special focus on theories of child development and early learning, play-based learning and shared partnership thus, emphasized the importance of considering such course as a professional development activity for the OCTs.

Finding of the current study revealed that highlighting the different rather than the complementary role of the members of the teaching team was troublesome in defining ECEs' roles and responsibilities in the FDK program. It is important to note that the review of Education Act 2014 (Part-X) and Ontario's leadership strategies: Principals wants to know: Supporting educator teams in the full day kindergarten emphasized understanding of the 
dynamics of the relationship among the educators through focusing on their distinct but complementary roles, instead of creating an "us versus” them situation. In one hand, the lens of “power/knowledge” suggests that acknowledging the complexities in relationships supports new perspectives to emerge and promote reflective practice among the educators. On the other hand, the lens of “hybridity” suggests ECEs’ perceptions of their differentiated roles were nothing but the reflection of their experiences of role negotiation during the hybridization process, and their thirst for recognition of the ECE profession and their complementary roles within the public school sphere.

\section{Power dynamics between ECEs and OCTs}

Participants of the current study reported power dynamics in the form of hierarchy and differences in professional status and educational background of the educators. Participants seemed to be careful about discussing the power issue between the members of the teaching team, because, they did not report their own experiences instead indicated mostly what happened in other classes. However, participants conveyed that power imbalance existed in the FDK classroom. One ECE participant mentioned that on her first day in the FDK classroom she was informed by her OCT that she (OCT) was the decision maker in the classroom. This comment indicated power relations with the OCT influences the ECE's own identity in order to cease the power of the ECE within the teaching team. Another participant mentioned,

I think I have been very lucky in my school and in my bond with OCT. I have heard from other that they run into an issue with personality conflict or, may be the OCT and ECE would prefer to have their own room or, their own set of rules, or, something, it is just separating the classroom. (Interview participant 1)

The participant suspected the educational background as the potential factor for the conflict between the ECEs and OCTs, and stated, 
We hear all the time OCTs are referred as quote on quote teacher-teacher in the room and we are just like the daycare or the ECE. The ECE is fine, but the daycare is not so much. I think that this was that even if you have three years of learning, four years of learning that's kind of how you perceived, and perceived how long you have been in school for. (Interview participant 1)

The “power/knowledge” lens here indicates how OCTs' educational background portrayed them more powerful compared to the ECEs within the ongoing discourse. The participant further discussed that ECEs learn more about behavioral and OCTs focus more on academic-based and referred OCTs as “book-smart”. She highlighted that ECEs learn a lot about children’s development in the early stage because professionally they deal with very young children. She further argued that OCTs were unaware of the fact that literacy and numeracy development learning is embedded in the typical pathways of children's development. She emphasized that "learning through working is more valuable than learning in the classroom as it provides the opportunity to apply the knowledge” (Interview participant 1). This illustrates how within the power relations, the ECE critically reflects on her complex relationship with the OCT and takes an activist's position to define her own identity.

ECEs’ concern about labeling them as “daycare worker” or "babysitter” was also evident during the FGD. One FGD ECE participant stated, “It’s not daycare. We are not glorified babysitters, right. We are in a school. There is professionalism, almost like a pride of working.” This is also suggests a hierarchy the ECE is positioning between ECEs that work in a day care and those that work in schools. Another interview participant stated, "I have got dozens of emails, questions, phone calls saying, my teacher does not need my information. What do I do?” (Interview participant 3). 
The FGD participants highlighted that although administrative effort was there to establish collaboration between the staff, there were ongoing problems regarding superiority issue and stated,

....it was delivered (by the administrator) to both of us (ECE and the OCT) at the time was you are a team, and thou shalt be a team, and it worked out wonderfully but there has been issues in other classrooms, and with other colleagues of mine, where thou shalt be a team under no circumstances without having any feeling of superiority. (FGD ECE participant)

Another FGD ECE participant added to it and mentioned that even though administrators saying about thou shalt, it is not an equal partnership in many respect, and she did not see it worked out well all the time.

\section{Analysis of theme with theory, literature and document review}

The key messages from this thematic finding suggest that ECEs identified the need for professional recognition of their work within the FDK program. Furthermore, a critical understanding of the policy directions is required on principals' part to better support the educator team. Such findings highlighted the power relation between the members of the teaching team.

The first issue that came up in the findings was ECEs' concern about the traditional notion of their role as "babysitter" or labeling their profession as "daycare”. The ECE participants of this study found it problematic and seemed to be very sensitive about professional recognition of the holistic nature of their work. The Pelletier (2014) study also highlighted similar findings about power imbalance in the FDK classroom and quoted it as one of the “greatest challenges of the FDK model” (p. 17). Pelletier, 2014 and Vanderlee et al., 2012 suggest that inequalities in working conditions and the leading role of OCTs' within the teaching team and in the classroom and coincided with the findings within the current theme. The 
leadership role of the OCTs' was also evident in the review of the Ethical Standards for teaching profession which focused on OCTs' leadership role in facilitating students' success that is embedded in their shared responsibilities. Understanding and valuing ECEs' profession and recognizing their complementary role seemed to be recurring concepts within this study. This correlated with Hauser and Jipson (1998) and Harwood, Klopper, Osanyin and Vanderlee (2013) study that highlighted how care and education operates in an integrated way when it comes to young children, and argued that professionalism within the ECE field is resistant to draw any line between these two areas. This was evident in the findings of this study as one of the interview participants highlighted this interwoven nature of children's learning and referred it as "crisscrossed" rather than two separate entities.

The second issue related to power dynamics between the members of the teaching team focused on the diverse educational background of the educators that, one ECE participants raised as a potential reason for the conflict between the two educators. The difference in educational background and OCTs' lead responsibilities were also mentioned in the study findings (Gibson \&Pelletier 2011; Gananathan, 2011) as potential factors for hierarchy and conflict. However, findings revealed that legislative changes under Bill 242 allowed both educators to perform the lead role in their respective area, such as OCTs in preparing report cards, class management, preparation of teaching plan etc. and ECEs in the delivering the extended day program(Ministry of Education, 2010). Thus, the complementary roles and shared responsibility of the educators is highlighted in the regulation.

In one hand, considering the issue of power dynamic through the lens of "Other" highlights how focusing on the educators' differentiated roles and professional backgrounds acted as a barrier in strengthening their teaching partnership. Like colonizers, OCTs viewed 
ECEs as strange and unfamiliar entities, the "Other” in the educational setting of school, and constructed the image of ECEs based on their traditional notion of "babysitter". On the other hand, the "power/knowledge" lens here suggests how power in its oppressive form operated in between the educators and constructed the ECE identity based on the taken for granted assumptions.

In addition, the meaning of leadership or the leading role recommended in the legislation seemed to have a superficial interpretation among the educators. These issues together fueled the hierarchical conflict between the educators. In the Education Act 2014 (Government of Ontario, 2014), preparation of report cards, evaluation of students’ progress, training, classroom management, and preparation of teaching plan were outlined as OCTs' duties in addition to sharing their other responsibilities with the ECEs, whereas, the Ethics and Standards for teaching profession emphasized on their leadership roles in promoting students’ success as part of their shared responsibilities.

The review of the Education Act 2014 and Ethics and Standards for teaching profession conveyed one common message emphasizing on sharing responsibilities to form collaboration for the success of the students. Focusing superficially on the meaning of leadership might be interpreted as power, control or domination that coincided with the findings of this study. However, looking deep into what outlined in the legislation and in the Ethics and Standards for teaching profession was helpful to develop a new insight about leadership. In the context of the current study, interpreting leadership as taking initiative to use each educator's distinct expertise that complements the expertise of another educator was helpful to see the collegial partnership that could take place among the educators. The "power/knowledge” lens here highlighted how power integrates through the discourse and influences our construction of individuals' identities. 
However, this also shows that reflecting critically on the discourses supports our understanding of the underlying complexities of power relations and opens up spaces for new perspectives to emerge.

The negotiation of new partnerships and identities in the process of hybridization, and according to the concept of "hybridity", is not an easy task. However, the review of the Ethical Standards of both teaching and early childhood profession suggested a "third space" that underpinned care, respect, trust and integrity as a core set of beliefs and values for both professions (College of Early Childhood Educators, 2011; Ontario College of Teachers, 2000). Both post-colonial and post-structural perspectives support an understanding of the complex relationship between the educators, thus allowing us to see how their relationship within the teaching team evolves at different time points. Considering the core set of beliefs and values as the basis of both professions suggested possibilities for negotiating the identities of the ECEs and OCTs in a way that strengthen their collegial partnerships and emphasize their complementary roles. As discussed in theme 1, ECEs' perceptions of their complementary role and their need for professional recognition were also persistent within the current study findings.

\section{ECEs' agency}

Despite participants discussed their role confusions and experience of power imbalance, data showed that ECEs seemed to start finding their voice within the FDK program as they discussed strategies to improve the teamwork by having an open mind, accepting new changes, improving interpersonal communication, obtaining freedom and flexibility for making choices and having a union. In addition, they discussed their passion for their work and their need for improving their expertise through professional development initiatives. Both ECE and OCT suggested ways to improve their teaching partnership. One interview participant mentioned, 
I just find that being with someone for more than one year can really help the program to grow in Ministry's image of what full day kindergarten program is, so not necessarily any personal challenges with the person. It takes time to build the relationship. The first year is just getting to know each other....so, I just kind of think you shouldn't change school every year. (Interview participant 2)

This suggests how over time identities shift and emerge depending on the “power/knowledge” relationships that are circulating throughout the discourse at each point of time. Another participant highlighted that freedom of choice and acceptance of change is necessary for the partnership to work. She mentioned that working within the teaching team seemed like a great opportunity to change the mind and start thinking in a new and different ways. She emphasized that learning to share and bonding together was really important for her and stated, to be role model for the children, if we don't go along together, what is the message you are sending to your classroom?” (Interview participant 1). Keeping an open mind and be respectful to partner's values and beliefs came up as good strategies to build partnership and correlated with values and beliefs of the ECE profession (College of Early Childhood Educators, 2011).

Another educator stated,

There is no reason to say that you are perfect, that is the way it should be done, or I am the way it should be done. You need to collaborate about what works best for the class, for those children, and for the most part. (Interview participant 2)

One of the teacher participant said that "I think it's great not having those regimented rules that the teacher does this, ECE does that because it gives us that flexibility, and I think the more we understand that the better” (FGD Teacher participant) The FGD teacher participant emphasized the complementary role of the educators in the teaching team and stated,

My interpretation is that your background is like the ELECT document, like personal social development, emotional social development and our background is more in being trained in how to do running records and how to do guided reading, shared reading, 
modeled reading and for writing and math....they are very symbiotic, and they are to complement. I would say you are the curriculum expert and your partner is the child development experiential expert and it makes sense to marry the two, but it's really hard. (FGD teacher participant)

This illustrates participant's understanding of both educators' complementary roles. A postcolonial perspective here supported understanding of educators' relationship that formed in the process of hybridization. This relationship was also depicted and emphasized in the analysis of the document (Ontario Ministry of Education, 2012). Moreover, the "power/knowledge” lens here supports understanding of circulation of power $r$ between the educators within the FDK classroom. Such understanding was helpful to see how OCTs' knowledge of curriculum and ECEs' knowledge of child development and play-based learning allow them to exercise power in the FDK classroom at different time points. Thus, power in its productive form allows educators to engage in reflective practice.

ECEs passion for continuing their work was evident across the data set. Most ECEs expressed their love for the children and their intrinsic motivation to pursue their work in the field during the FGD and interview. During the FGD, one ECE participant stated that despite of her low wage she contributed to buy supplies for the classroom. She described that as ECE they always do it and that was something special about ECE. Another FGD ECE participant stated that she took a $\$ 10$ an hour pay cut from her salary to do her ECE because that was what she always wanted to do, this was what she was passionate about. She also mentioned that she was teacher at heart and that is why she joined the kindergarten program.

One of the FGD ECE participants stated,

I love my job. I love what I do. I love being in the classroom with my teaching partner.... I am doing what I want to do. I love what I am passionate about. I love to see more team building, more collaboration, more understanding of what our roles are and how to make it work. 
Like the FGD participants, the interview participants also discussed their passion for their work. One of the participants stated, “wherever I am, as long as it it’s the young children, I am happy, I find it is a good place to work". She also expressed her thoughts about the positive impact of FDK program on children and how much they enjoyed it. She stated, "This little girl in our class the other day, it was at the end of the day and she was like, I just love it, love it, love it the extended day time!”

Two of the interview participants mentioned that because of their supervision duty they missed their time which they would like to spend with the children in the classroom. Another interview participant mentioned how she spent her personal time for work even if it was unpaid and just because she felt passionate about it.

Yes, it's kind of hobby for me because I am little bit over the top. I can be there until the custodian takes me out until 11:30 in the night...I do spend a lot of my own time for preparing, organizing, planning and cleaning, that kind of stuffs." She continued Yes, it is unpaid, but I have worked as an ECE and that's part of the life of an ECE.

ECEs passion for continuing in the FDK program became more evident as they emphasized the need for their professional development. One of the FGD ECE participants stated, “ I can’t do running records. Some of it is expertise and I am willing to learn some of the things, the literacy part”.

An interview participant described how she was lucky to be picked up by her principal for professional development activities and stated, "I do lot my professional development after school that my administrator, my principal sees that and luckily picks me to go to a lot of the PD activities”(Interview participant 2).

Another participant mentioned, "I think that the accreditation of ECE and OCT somehow should be more on the same level. We should be more the same as we are doing pretty much the same job” (Interview participant 1). She further argued that as ECEs' training focused more on 
development and behavioral, OCTs' on academic, therefore, “more developmental courses for OCTs and a little bit of learning types things for ECEs.” She suggested that instead of focusing on the types of Degree such as Bachelor or Masters, there should be a generic component to come out with, and the Degree or Diploma should be in the specialized area that someone would like to teach in FDK.

One of the FGD participants stated,

I am really excited to be part of this program. The only thing that I had wished....would be a little bit more preparedness for us, some kind of even PDs, or, coaching or, mentoring...we are in our fourth year and I feel like they have kind of thrown us in and said sink or swim... working in a child care is completely different than working in a school. We weren't taught running record, we weren't taught guided reading, we weren't taught numeracy even. It was all play based for me.

She further continued, "I'm on board to trying and learning and growing together with my team partner and with the rest of the team. I just need a little bit more support from the overhead and also PD together, collectively”. This suggests that in search for their agency ECEs identified the need to establish their authority in their relationship with OCTs.

One of the FGD teacher participants mentioned the importance of considering AQ course as professional development activity in order to better understand ECEs' role and their background and the FDK program. She stated, "I would kind of say AQ, being able to work together with everybody so the understanding of the AQ both on the ECE and the teacher side. Trying to have consistency”. Some of the participants mentioned the difference having a union for the ECEs can make. One of the FGD teacher participants suggested to have a separate union for the ECEs and stated,

I'm finding with the ECE you are part of ETFO and we kind of need your voice at the table, and we're thinking she has been here since 8:10 this morning....you know they are just seems to be an extra 10 minutes here, an extra half an hour there..we all go above and beyond., absolutely, but they don't have someone they can call. 
Another interview participant suggested,

We need to find ways to make more of an union of the OCTs and ECEs...that would be a mixing...if we have somehow a core joining union, that would have been unified literally the bonding and regulation between OCTS and ECEs.

\section{Analysis of theme with theory, literature and document review}

The key message that from this thematic finding highlighted ECEs' activist positions in order to establish their authority within the teaching team. ECEs' passion for their work, their need for freedom, collaboration, professional recognition, and support from the administrator, their motivation for professional development, and lastly their demand for a union, collectively represented ECEs' search for their own agency within the FDK program. Moreover, these findings correlated with Harwood et al. (2013) study findings where ECEs recognized the embedded nature of their role within the ecology of child development and expressed their need for supports to function within each system. One important finding within the current theme was ECE's consideration of working within the teaching team as an opportunity for change, growth and development. Participant's such perspective perfectly coincided with the theoretical framework considered for this study and reflected the activist position she took. Taking the position of an activist was crucial for the ECEs to raise their voice in order to change the traditional notion of their roles and responsibilities.

As ECE participants discussed about their bonding with the other educators in the team and their complementary roles, they exhibited their ongoing negotiations of identities. Similar findings were revealed in the Tozer (2012) study where participants collaborated with their teaching partners despite many challenges. It was also interesting to note that one of the FGD 
teacher participants recognized and mentioned the complementary skills ECEs offered within the teaching team.

ECEs' passion for their work with young children reflected Nodding's (1984) concept of mutuality that highlighted care as the basis of reciprocal teaching-learning process between the educators and children. Similar findings were also discussed by Harwood et al. (2013) regarding ECEs' love for their work and the children. Interestingly, care was mentioned as one of the beliefs and values that underpinned the Ethical standards for early childhood and teaching professions and depicted in the review of the documents Code of Ethics and Standards of Practice: Recognizing and honoring our profession, and Ethical Standards for Teaching Profession and Standards of Practice for Teaching Profession. ECEs' passion for their work and recognition of their new identities were further emphasized when they mentioned about their needs for professional development, collaboration and understanding of their roles. Because of the different educational and training backgrounds, both ECE and teacher participants highlighted training needs that would help them to better understand their teaching partners' complementary roles, such as “Additional Qualification Course Kindergarten part 1” and developmental courses for the OCTs and literacy training for the ECEs. Similar kind of training need for ECEs was discussed in Corter, Janmohamed and Pelletier (2012) study. Moreover, recognizing the ECE profession through having same accreditation like the OCTs' was also suggested by one of the participants of the current study. Need for recognition of ECEs' profession and their complementary roles within the teaching team emerged across all themes. Although not many, but two of the participants of the current study mentioned about having a union for the ECEs, which was not also evident in the review of the literature for this paper. However, this suggests the need for a platform for the ECEs so that their voice can be heard. 
Utilizing the lens of "hybridity" and "power/knowledge" was helpful to understand how within the process of hybridization ECEs were searching for their agency which would lead them to have their own authority within their power relationship in the teaching team. Looking at ECE participants' need for professional development in order to better understand the complementary role of their partner emphasized that ECEs were searching for authority in their relationship with their teaching partners. This correlated with Langford (2010) study findings that highlighted ECEs' exercise of authority in their relationship with people who are part of ECEs' professional practice and offer new perspectives. This authority would not coincide with the traditional definition authority mentioned in the review of the literature for this study, rather would be based on a "respectful and trusting relationship" (Langford, 2010, p. 298). The review of Ethics and Standards of practice for both ECE and teaching profession also emphasized ECEs or OCTs build a respectful and trusting relation with their students, families and colleagues. Viewing this respectful and trusting relationship through the lens of "hybridity", "third space" and "power/knowledge" allows ECEs and OCTs a space to speak for them, make choices, to negotiate their identities, to have open communication, and share experiences. Most importantly, engaging in such reflective practice allows ECEs to take the control of meaning making of their

ECE identities from an activist position and to influence the dominant discourse leading to change the taken-for-granted assumptions about their ECE image. Understanding and valuing the shared responsibilities through establishing a relationship based on care, respect, trust and integrity is the core of successful implementation of the teaching team.

\section{Summary of the findings}

From the analysis of three major thematic findings, I found that despite their experiences of challenges, ECEs recognized and acknowledged their complementary roles within the 
teaching team. They also identified the need for professional recognition of their ECE work within the teaching team and in the FDK program. However, I also found principals need to have a greater understanding about educators' relationship, and the policy directions to better support the educator team. Most importantly, my findings highlight that in search for their agency, ECEs took the activist positions in order to establish their authority within the teaching team.

As unexpectedly OCTs were also part of this study, the methodology and the postcolonial lens chosen for this study allowed me to shift positions between ECEs and OCTs in order to unmask the lived realities of ECEs within the teaching team, also in the FDK program. In addition, the lens of "power/ knowledge" was helpful for me to understand educators' complex relationships within the teaching team with a focus on how power circulates within this relationship and opens up possibilities for new bodies of information and knowledge to emerge. Such understanding supported me to think differently as I was exploring how ECEs' lived experiences in the FDK program shaped their perceptions of their roles and responsibilities in the FDK program. 


\section{Significance of the study}

The purpose of the study was to understand early childhood educators' (ECEs)

perceptions of their roles and responsibilities in the full day kindergarten (FDK) program based on the lived experiences. As an early childhood professional, my involvement in the recently initiated universal preprimary education program in Bangladesh, and in a competency based training program designed to build the professional capacity of the teachers and early childhood educators together, encouraged me to undertake this study. The similarities between universal preprimary program in Bangladesh and full day kindergarten program in Ontario, such as moving early learning into the public school sphere, introduction of play-based curriculum, educational background, improved working conditions, nature of training of the teachers and early childhood educators fueled my interest to become involved in this study.

To learn about ECEs' perceptions of their roles and responsibilities in the FDK program in Ontario, I conducted a literature review. Although study findings (Ministry of Education, 2013; Pelletier, 2014) highlighted factors such as role confusion, hierarchy in educators' status, working conditions etc. hindering the performance of the teaching team however, finding literature which has a specific focus on ECEs' perceptions of their roles and responsibilities in the FDK program was challenging. This motivated me further to formulate research questions that solely focus on ECEs' perceptions of their roles and responsibilities in the FDK program.

Understanding how ECEs conceptualize and describe their roles within the FDK program was crucial to answer the research questions I asked in this study. The selection of a qualitative approach and a theoretical framework underpinning post-colonial and post-structural theories allowed the participants of this study to express their views based on their lived experiences. As a student researcher, it was also helpful for me to develop new insights regarding ECEs' 
perceptions of their roles and responsibilities from a different perspective. In addition, pursuing the study in this area was crucial to inform my professional practice in the field of early childhood development and education in Bangladesh and in Canada.

The teaching team is at the core of the FDK program and successful implementation of the FDK program greatly depends on the successful collaboration within the teaching team (Pascal, 2009). Key messages from three major thematic findings suggests ECEs’ recognition and acknowledgement of their complementary roles within the teaching team, their desire for professional recognition of their ECE work, and their activist positions to establish their authority within the teaching team. Moreover, key messages emphasized the need for a greater understanding about educators' relationship among the principals. From the lens of post-colonial concepts and Foucault's “power/knowledge”, the abovementioned findings illustrate how ECEs’ in their complex relationship with their teaching partners become "critically reflective educators" (Mac Naughton, 2005) to understand and resist any oppressive form of power and to establish their authority in the FDK program. ECEs’ such authority does not comply with the traditional notion of authority (Langford, 2010) rather, encompasses care, respect, trust and integrity to establish a collegial relationship with their teaching partner. Such findings from the study have potential to inform the implementation process about ECEs' experiences of their new roles in the program in order to consider further steps so that the teaching team can maximize its collaborative expertise. The findings of the study may be helpful for the members of the school board to have a clear understanding of the ECEs' roles in the FDK classrooms. In addition, the findings of the study may also provide ECEs opportunity to reflect on how they construct the perceptions of their new roles based on their lived experiences in the FDK program. 


\section{Final Comments and recommendations}

This study is one-step towards understanding ECEs’ perceptions of their roles and responsibilities in the FDK program in Ontario. Findings of this study suggest that valuable information can be gathered based on ECEs' lived experiences in the FDK program. Choosing qualitative approach guiding the selection of methodology was helpful to collect data by talking directly to the ECEs through Focus Group Discussions and interviews, and this involved the opportunity to have OCTs on board.

The post-colonial lens was instrumental to shift position and interpret ECEs’ lived experiences from their position rather than adapting the expert role. It helped me to understand how the ECE role was perceived as “Other” (Child \& Williams,1997) due to their unfamiliarity within the school community. In the context of the current study, post-colonial lens supported me to challenge the way ECEs were portrayed in the ongoing discourse and to develop a new perspective to examine ECEs shaped their perceptions about their roles based on the lived experiences. Additionally, considering the lens of "power/knowledge” supported me to understand and challenge the existing power issue between the members of the teaching team, also to examine ECEs’ lived experiences from multiple perspectives.

The review of the documents was helpful to understand the distinct expertise of the members of the educator team, and how their expertise are combined in a complementary role to deliver the full day kindergarten program. Reviewing the documents supported me to understand how the ECE role in the FDK program is outlined in the regulation based on their professional knowledge and background. Here, the lens of post-colonial concepts and Foucault's concept of “power/knowledge” was crucial to gain a deeper understanding of the policy discourse in order to reveal ECEs’ distinct but complementary roles, ECEs’ opportunity to exercise the power in 
its productive form, and how their roles can be supported through the leadership of the principals to enhance the performance of the teaching team.

Key messages from the thematic findings suggest that despite their experiences of challenges in the FDK program, ECEs recognize and acknowledge their complementary roles within the teaching team. In addition, ECEs identified the need for professional recognition of their work and took activists positions to establish their authority within the teaching team. Vanderlee et al. (2012) suggests that the professional image of the ECE needs to be clearly articulated in the regulation in terms of their shared responsibility within the teaching team. Understanding the ECE role is crucial to enable ECEs to transfer and implement their ECE knowledge and training from childcare to the FDK classroom in order to create an optimum learning environment for children. Moreover, articulating ECEs' roles and responsibilities in the FDK program would help the both educators to engage in reflective practice in order to accept differences and bring new changes into their pedagogical practices within the FDK classroom. Such, engagement would allow the educators especially, the ECEs to construct their own identities.

Key messages from the thematic findings also emphasized the need for a greater understanding about the relationship between the members of the teaching team among the principals. As principals are already familiar with the knowledge and educational background of the teachers, understanding of ECEs' knowledge, professional practice and their roles in the FDK program would help them to better understand the dynamics of educators' relationship in the teaching team. Such understanding would allow principals to promote collaboration between the educators in order to establish a collegial relationship. 
Lastly, the key messages from thematic findings of this study are crucial for the policy makers while professionalizing the ECE field. Barnett's (2004) study suggests that educational background, professional development and training are important considerations for policy makers and educators while professionalizing the sector; therefore, understanding ECEs' perception of their roles and responsibilities is vital for policy-makers. In addition, a critical understanding of the policy directions is required to better support the educator team in the FDK program. This suggests much attention is required to bridge the gap between knowledge and practice at the policy level. As the implementation of FDK is at the forefront of ongoing discourse, therefore, systematic change is required for more professional learning through collaboration and networking among different school boards, principals and the educator team. Such collaboration and networking are beneficial for gaining a common understanding about the complementary role of the members of the teaching team. Cantalini-Willams and Telfer (2010) suggests, "coherent, consistent and collaborative professional learning is essential for the implementation of a quality Full-Day Early Learning Kindergarten program” (p.6).

I propose this study can be a cornerstone of understanding the ECEs' perceptions of their roles and responsibilities in the FDK program and within the realm of education. Findings of the study may have important implications in term of enhancing the performance of the members of the teaching team in the FDK program. However, further research initiative is required to investigate how ECEs working in other school boards construct their perception of their roles and responsibilities based on their lived experiences. If positive change is desirable within the teaching team, we need to see the roles of the members of the teaching team beyond their binary positions and closed identities (Bhabha, 1994). From the standpoint of ECE, "I love my job. I love being in the classroom with my teaching partner. I love to see more team building, more 
collaboration, more understanding what our roles are and how to make it work”. Having a greater understanding of the ECE role has the potential to enhance the performance of the teaching team, and a collaborative and reflective team is required for successful implementation of the FDK program in Ontario. 


\section{Appendix A: Interview guide}

1. How many years of experience do you have as an early childhood educator?

2. What level of education have you completed?

3. What hours do you normally work during a regular school day/year?

4. Describe your role in the FDK.

5. How does your role differ compared to a teacher's role in classroom?

6. Describe your experience in the FDK classroom.

7. Describe what you think your role in the FDK should be.

8. What are your thoughts on ECEs professional development?

9. Describe what kind of support do you get as an ECE to perform your role as a member of the teaching team? 


\section{Appendix B: Focus Group Discussion Question guide}

1. Describe your experience in the full day kindergarten.

2. What motivates your decision to work with the school board?

3. Describe your new role as an educator in the full day kindergarten classroom.

4. How does your role differ compared to a teacher's role in the full day kindergarten?

5. Describe the role of the school board. 


\section{Appendix C: Recruitment email for potential participants for phone interview}

Hi!

Thank you so much for the support.

I am doing my MA in Early Childhood Studies at Ryerson University in the Early Childhood Studies Program. In order to complete my Major Research Paper (MRP), I am assisting as a team member of the 'Schools at the Centre of the Community: A Case Study of Seamless Day Early Learning' research project under the guidance of Dr. Zeenat Janmohamed. Through my MRP research, I am looking at the early childhood educators' perceptions of their roles and responsibilities in the full day kindergarten program. My plan is to collect data from the early childhood educators through Focus Group Discussion (FGD) and interviews.

However, I have data from one FGD and now having difficulty in recruiting participants for the interview. It would be helpful to interview 4 RECEs over the phone in order to fulfill my MRP requirements, and your support will be highly appreciated. My phone number is 6476074564 and I will also be available via email at rabeya.hossain@ryerson.ca

Thanks again.

Best regards

Rabeya 


\section{Appendix D: Information Letter and Consent form}

\section{Early Childhood Educator and Teacher Information Letter and Consent Form}

\section{Dear Educators:}

This research project aims to develop a case study of the implementation of full day kindergarten and school based extended day programs for young children in the Waterloo Region. As a Visiting Scholar at OISE, of the University of Toronto in the Applied Psychology and Human Development Department, I am conducting a research project entitled, "Schools at the Centre of the Community: A Case Study Seamless Early Learning”.

The Waterloo District School Board is one of the few school boards in Ontario implementing a vision to ensure that children's experiences are focused on optimal learning opportunities within a supportive family and community context. The collaborative nature of the working relationship with the school board, the region and community partners provides an opportunity for learning and long term planning for other communities and will inform the development of a provincial strategy. I am working with Dr. Jenny Jenkins and a team of partners from the school board, the region and community agencies in the development of this project.

The purpose of this study is to investigate the following:

1. To examine the implementation of seamless early learning in the WRDSB through the development of a case study that explores the partnership between the school board, the region and community partners.

2. To promote lessons from the collaboration in the your community by examining factors related to excellence in early learning professional practice and to develop popular education material based on the case study.

3. To explore the establishment of a child and family centered school approach as an avenue to strengthen community development.

The Waterloo District School Board (WRDSB) has given permission for this study to take place in schools within the WRDSB, subject to the approval of the principal and the informed consent of all participants. I would like to request your participation in this study. Your participation in an interview will take approximately 60 minutes. The project also includes the development of a public education video to explain the key components of effective seamless programs. If you agree to participate in the video, the research team will make separate arrangements with you for videotaping. The videotaping will take another 60 minutes of your time and all taping will be done at the school. 
For the purpose of this study, we are primarily interested in interviewing educator teams in a focus group in FDK and extended day programs, principals on their experience of implementing FDK and Extended Day programs, and parents with children who access kindergarten and extended day services. This information letter provides background for the study you are being asked to return the signed or blank consent form in a sealed envelope to the researcher.

The name of the schools, educators or parents who choose to participate will NOT be used in this study in any way. All participants will be given a number code to order to maintain anonymity. All information collected during the interviews will be kept strictly confidential and parents, children, and schools will not be identified individually unless I agree to take part in the making of the video for public distribution. In that case, my identity will be known.

The results of this study will be sent to all educators, parents and school principals who participate. Records will be destroyed after 5 years.

Your participation is this study is completely voluntary.

If you have any questions about the study, please feel free to contact me. Please read and sign the attached consent form and indicate whether your school wishes to be involved. If you wish to speak to someone not associated with the study, you can contact the Office of Research Ethics (ethics.review@utoronto.ca, 416-946-3273).

Thank you kindly for your consideration.

Sincerely,

Zeenat Janmohamed

Visiting Scholar

OISE/ University of Toronto

Phone: (647) 981-5217

E-mail: Zeenat.janmohamed@utoronto.ca 


\section{CONSENT FOR EDUCATORS}

Research Project Title: Schools at the Centre of the Community: A Case Study of Seamless Early Learning

A signed and dated copy of this consent form will be left with you. Together with the information sheet, it should give you the basic idea of what the research is about and what you are being asked to do. Please take the time to read this and the information sheet carefully. Feel free to ask questions about anything that is unclear before you sign.

I, , understand that this study is looking at how the implementation of school board operated extended day programs affects my working partnership with my co-workers. The study also explores how access to extended day programs impacts on parents' ability to manage family life, work or study. This research will help us understand what is important for collaborative partnerships that support children's learning experiences, educator teams and family's interests. Researchers from the University of Toronto are carrying out the study.

I understand I will now take part in an interview that will last around 60 minutes. I know I do not have to answer any questions I don't want to. I may skip activities that I feel uncomfortable with or stop the interview at any time.

As part of the interview, I know I will be asked to discuss my professional experiences as part of an educator team in FDK and extended day programs delivered by the school board. I am assured that all information collected from me will be securely stored. It will only be associated by an identification number. I understand that this information will be stored in this way for 5 years by the researchers. I agree that I may be contacted after this present study is over to take part in future studies. I will be given details of any new studies and will be asked to take part. If I agree, I will sign a new consent.

All information collected will be kept confidential. Neither my name nor the name of my school will be used in connection with this study. Any results will be reported on a group level. Identification numbers will be used so that my name and the name of my school will not be stored with the information collected.

I understand that taking part in this study is voluntary I know that I can stop taking part at any time without explanation, even after I have signed this form. 
I understand if I have questions about my rights as research participant I can contact University of Toronto Office of Research Ethics by e-mail ethics.review@utoronto.ca or phone 4169463273.

I understand if I have questions about this form or the study, I can call the Research Coordinator, Mira Boskovic (Telephone: 416-978-0992) or Zeenat Janmohamed (Phone: (647) 981-5217)

I agree to take part in this study. $\square \quad$ I agree to take part in the video.

Signature:

Date: $(\mathrm{DD} / \mathrm{MM} / \mathrm{YY})$

Name: (PLEASE PRINT) 


\section{Appendix E: Notice for recruitment of participant for phone interview}

Good Morning everyone,

The Atkinson Center at OISE and the WRDSB are collaborating on a research project on

seamless early learning. As part of the project we are conducting research around the perception

of the roles and responsibilities of all educators implementing the full day kindergarten

programs.

Those educators that have participated, we thank you for the time you have taken to contribute you perspective.

We are hoping to connect with four more Early Childhood Educators in relation to their perception of their roles in the full day kindergarten program.

Should you wish to be a part of this exciting research project, please contact at Rabeya Hossain rabeya.hossain@ryerson.cato participate in a phone interview. Thank you in advance for your support. 


\section{References}

Barnett, W. S. (2004). Better teachers, better preschools: Student achievement linked to teacher qualifications. Preschool Policy Matters (2). New. Brunswick, NJ: National Institute for Early Education Research. Retrieved from http://nieer.org/resources/policybriefs/2.pdf

Bhabha, K. Homi. (19994). The location of culture. New York, NY. Routledge.

Bresner, K. (2010) Othering, power relations, and indigenous tourism: Experiences in Australia's northern territory. Platform .11. Retrieved from

http://journals.uvic.ca/index.php/platforum/article/download/2197/859

Caldwell, R. (2007). Agency and change: Re-evaluating Foucault's legacy. Organization, 14(6), 769-791.doi:10.1177/1350508407082262

Cantalini-Williams, M., Telfer, L., \& DSB, B. H. N. C. (2010).Successful implementation of the full-day early learning-kindergarten program. Principal Connections, 14(1), 4-7. Retrieved from http://eyeonkids.ca/docs/files/canatlini-williams_full_day_leadership\%5B1\%5D.pdf

Callaghan, L. L. (2012). Examining the collaborative structure in full day kindergarten educator teams. (Order No. MR84427, University of Windsor (Canada)). ProQuest Dissertations and Theses,167. Retrieved from http://ezproxy.lib.ryerson.ca/login?url=http://search.proquest.com/docview/1175321449?acco untid=13631. (1175321449).

Childs, P., \& Williams, R. J. P. (1997). An introduction to post-colonial theory. England: Prentice Hall.

Corter, C., Janmohamed, Z., \& Pelletier, J. (Eds.). (2012). Toronto First Duty phase 3 report. 
Retrieved from

http://www.oise.utoronto.ca/atkinson/UserFiles/File/About_Us/About_Us_What_We_Do_TF D/TFD_Phase3Report.pdf

College of Early Childhood Educators. (2011). Code of ethic and standards of practice: Recognizing and honoring our profession. Retrieved from http://www.collegeece.ca/en/Documents/Code_Ethic_English_Web_August_2013.pdf

College of Early Childhood Educators. (n.d.). Ethical \& professional standards for early childhood educators: Promoting excellence in professional practice. Retrieved from http://www.collegeece.ca/en/Documents/CECE_Brochure_Code_Ethics_Standards_Practice_English_WEB.pdf Creswell, W. J. (2014).Research Design: Qualitative, quantitative, and mixed method approaches. California, CA: Sage Publications Inc.

Directorate of Primary Education. (2012). Pre-primary expansion plan. Retrieved from http://www.dpe.gov.bd/wpcontent/uploads/2014/PPE/ppe_ep_\%20final\%20version\%20060313.pdf

Foucault, M., \& Gordon, C. (1980). Power/knowledge: Selected interviews and other writings, 1972-1977. New York, NY: The Harvester Press.

Foucault, M. (1988). Michel Foucault: Politics, philosophy, culture: Interviews and other writings. In L. Kritzman (Ed.). London, UK: Routledge.

Friendly, M. \& Prentice, S. (2009). About Canada: Childcare. Canada: Fernwood Publishing.

Gibson, A. \& Pelletier, J. (2011). Can we work together? Preliminary findings from an examination of ECE and teacher dynamics in full-day early-learning kindergarten. Retrieved 
from

http://www.oise.utoronto.ca/atkinson/UserFiles/File/SI2011_Poster_ECEandKteacher.pdf

Gibson, M.(2013). Producing and maintaining professional identities in early childhood.

Retrieved from http://eprints.qut.edu.au/62396/1/Megan_Gibson_Thesis.pdf

Government of Ontario.(2007). Early Childhood Educators Act, 2007 Chapter 7, definitions 1 \& practice of early childhood education 2 . Retrieved from http://www.elaws.gov.on.ca/html/statutes/english/elaws_statutes_07e07_e.htm

Government of Ontario.(2014). Education Act. Retrieved from http://www.elaws.gov.on.ca/html/statutes/english/elaws_statutes_90e02_e.htm\#BK437

Government of Ontario. (2009). Ontario College of Teachers Act, 1996. Retrieved from http://www.e-laws.gov.on.ca/html/statutes/english/elaws_statutes_96o12_e.htm\#BK4

Harwood, D., Klopper, A., Osanyin, A. \&Vanderlee, L., M (2013). 'It's more than care': Early childhood educators' concepts of professionalism. Early Years, 33(1), 4-17

Hauser, E., M. \&Jipson, A. J. (1998).Intersections: Feminisms/Early childhoods. New York, NY: Peter Lang Publishing Inc.

Huddart, D. (2006). Homi K. Bhabha. United Kingdom, UK: Routledge.

Johnston, I., \& Richardson, G. (2012). Homi Bhabha and Canadian curriculum studies: Beyond the comforts of the dialectic. Journal of the Canadian Association for Curriculum Studies, 10(1), 115-137.

Langford, R. (2010). Theorizing an early childhood educator's authority for the advancement of social goods. Alberta Journal of Educational Research, 56(3), 291-303. 
Martin, S., Meyer, J., Jones, R., Nelson, L., \& Ting, L. (2010).Perceptions of professionalism among individuals in the child care Field. Child \& Youth Care Forum, 39(5), 341349.doi:10.1007/s10566-010-9107-5

Mac Naughton, G. (2005). Doing Foucault in early childhood studies: Applying poststructural ideas. Oxon, UK: Routledge.

Ministry of Primary and Mass Education. (2008). Pre-primary operational framework. Retrieved from http://www.unicef.org/bangladesh/Operational_framework_for_preprimary_education_English.pdf

Ministry of Education, Government of Ontario. (2013, October).A meta-perspective on the evaluation of full-day kindergarten during the first two years of implementation. Toronto, ON, Canada. Retrieved from http://www.edu.gov.on.ca/kindergarten/FDKReport2013.pdf

Ministry of Education (2010). Legislative changes under bill 242. Retrieved fromhttp://www.edu.gov.on.ca/eng/policyfunding/memos/may2010/2010EL6_Bill242.pdf Moss, P., \& Balduzzi, L. (2013).Early childhood and compulsory education: Reconceptualising the relationship. New York, NY: Routledge.

Nieuwenhuys, O. (2013). Theorizing childhood(s): Why we need postcolonial perspectives. Childhood, 20(1), 3-8.doi:10.1177/0907568212465534

Noddings, N. (1984). Caring, a feminine approach to ethics and moral education. Berkeley: University of California Press.

Ontario College of Teachers.(2014). Requirements for becoming a general education teacher in Ontario: Including multi-session programs. Retrieved from http://www.oct.ca//media/PDF/Requirements\%20General\%20Education\%20Teacher/EN/general_education_tea cher_e.pdf 
Ontario Ministry of Training, colleges and Universities. (2012). Early childhood education program standards. Retrieved from https://www.collegeece.ca/en/Documents/Early_Childhood_Education_Program_Standard_EN.pdf

Ontario Ministry of Education. (n.d.). Education Act, R.S.O. 1990, c. E.2.summary. Retrieved from http://lin.ca/resources/education-act-rso-1990-c-e2-summary

Ontario College of Teachers. (2000). The ethical standards for teaching profession and the standard of practice for the teaching profession. Retrieved from https://www.oct.ca//media/PDF/Standards\%20Poster/standards_flyer_e.pdf

Ontario College of Teachers. (2012). Foundations for professional practice. Retrieved from http://www.oct.ca//media/PDF/Foundations\%20of\%20Professional\%20Practice/Foundation_e.pdf

Ontario College of Teachers. (2013). Additional qualification course Guideline kindergarten, part I: schedule D teachers’ qualifications regulation. Retrieved from https://www.oct.ca//media/PDF/Additional\%20Qualifications/EN/Schedule\%20D/Part\%20I/i_kindergarten_e.pdf

Ontario Ministry of Education. (2010). Full-day early learning kindergarten program for fourand five-year olds: A reference guide for educators. Retrieved fromhttp://www.wecdsb.on.ca/pdf/jksk/Full-Day\%20Kindergarten\%20Educator\%20GuideFinal.pdf

Ontario Ministry of Education. (2012). Supporting the Ontario leadership strategy: Principal wants to know: Supporting educators teams in full day kindergarten. Retrieved from http://www.edu.gov.on.ca/eng/policyfunding/leadership/pdfs/issue16.pdf 
Ontario Ministry of Education. (2014, March 3). Leadership development: Principals want to know. Retrieved from http://www.edu.gov.on.ca/eng/policyfunding/leadership/principalsWanttoKnow.html Osterhammel, J. (2005). Colonialism. Princeton: Markus Wiener Publishers.

Pascal C. (2009). With our best future in mind: Implementing early learning in Ontario. Report to Premier of Ontario. Retrieved from http://www.ontario.ca/education-and-training/earlylearning-report

Pelletier, J. (2014). Key findings from year 3 of full-day early learning kindergarten in Peel. Retrieved from http://www.oise.utoronto.ca/atkinson/UserFiles/File/Publications/Key_findings_Yr_3_Mar_1 4.pdf

Pelletier, J. (2013). Ontario’s full-day kindergarten: A bold public policy initiative. Public Sector Digest.Retrieved from http://www.oise.utoronto.ca/atkinson/UserFiles/File/Publications/62014_-_Ontario_s_Full-day_Kindergarten_A_Bold_Public_Policy_Initiative.pdf

Pelletier, J. (2012). Key findings from year 1 of full day early learning in Peel. Retrieved from http://www.oise.utoronto.ca/atkinson/UserFiles/File/Publications/Peel_Year_1_FDELK_Sum mary_Report.pdf

Romain, M. \& Petersen, I. (2012). Full-day kindergarten: Early childhood educators reflect on their first year in the classroom. ETFO Voice, 14(2), 29-39. Retrieved fromhttp://etfovoice.ca/back-issues/2011/V14N2_WINTER_11.pdf

Said, E. (2012). Edward said on orientalism: Palestine dairy. Retrieved from http://www.youtube.com/watch?v=fVC8EYd_Z_g

Said, E. (1979). Orientalism. New York. Vintage Books. 
Tozer, C. C. (2012).The development of team relationships in teacher and early childhood educator(ECE) integrated staff teaching teams in full day, every day kindergarten. Retrieved fromhttps://tspace.library.utoronto.ca/bitstream/1807/34945/1/Tozer_Catharine_201211_PhD _thesis.pdf

Vanderlee, M-L., Youmans, S., Peters, R. \&Eastabrook, J. (2012). Final Report: Evaluation of the full-day early learning-kindergarten program. Retrieved from http://www.edu.gov.on.ca/kindergarten/FDELK_ReportFall2012.pdf

Viruru, R. (2005). The impact of postcolonial theory on early childhood education.Journal of Education, 33, 7-29. Retrieved from http://joe.ukzn.ac.za/Libraries/No_35_2005/The_impact_of_postcolonial_theory_on_early_ch ildhood_education.sflb.ashx 